\title{
Hypoxia Regulated Inhibin Promotes Tumor Growth and Vascular Permeability By ACVRL1 and CD105 Dependent VE-Cadherin Internalization
}

\section{Ben Horst}

University of Alabama

Shrikant Pradhan

University of Alabama

Roohi Chaudhary

University of Alabama

Eduardo Listik

University of Alabama

Alex Choi

University of Alabama

Michael Southard

University of Alabama

Yingmiao Liu

University of Alabama

Regina Whitaker

University of Alabama

Nadine Hempel

University of Alabama

Andrew Berchuck

University of Alabama

Andrew Nixon

University of Alabama

Nam Lee

University of Alabama

\section{Yoav Henis}

Tel Aviv University https://orcid.org/0000-0002-1408-3877

Karthikeyan Mythreye ( $\triangle$ mythreye@uab.edu )

University of Alabama https://orcid.org/0000-0001-5478-0098

Article 
Keywords: hypoxia, ovarian cancer, angiogenesis, permeability, inhibin

Posted Date: November 2nd, 2021

DOl: https://doi.org/10.21203/rs.3.rs-971293/v1

License: (c) (1) This work is licensed under a Creative Commons Attribution 4.0 International License. Read Full License

Version of Record: A version of this preprint was published at Communications Biology on June 2nd, 2022. See the published version at https://doi.org/10.1038/s42003-022-03495-6. 


\section{Abstract}

Hypoxia, a driver of tumor growth and metastasis, regulates angiogenic pathways that are targets for vessel normalization and ovarian cancer management. However, toxicities and resistance to antiangiogenics limits their use making identification of new targets vital. Inhibin, a heteromeric TGFb ligand, is a contextual regulator of tumor progression acting as an early tumor suppressor, yet also an established biomarker for ovarian cancers. Here, we demonstrate a previously unknown role for inhibins and find that hypoxia increases inhibin levels in ovarian cancer cell lines, xenograft tumors, and patients. Inhibin is regulated specifically through HIF-1, shifting the balance from activins to inhibins. Hypoxia regulated inhibin promotes tumor growth, endothelial cell invasion and permeability. Targeting inhibin in vivo through knockdown and anti-inhibin strategies robustly reduces permeability in vivo and alters the balance of pro and anti-angiogenic mechanisms resulting in vascular normalization. Mechanistically, inhibin regulates permeability by increasing VE-cadherin internalization via ACVRL1 and CD105, a receptor complex that we find stabilized directly by inhibin. Our findings are the first to demonstrate direct roles for inhibins in vascular normalization via TGF-b receptors providing new insights into the therapeutic significance of inhibins as a strategy to normalize the tumor vasculature in ovarian cancer.

\section{Introduction}

Changes in angiogenesis are associated with metastasis in most cancers, including ovarian cancers, with significant impact on tumor progression and ascites development in advanced disease ${ }^{1,2}$. As such, antiangiogenic therapies have had significant impact in the management of ovarian cancers ${ }^{3}$. However, their effectiveness can be frequently limited due in part to toxicities and acquired resistance, leading to challenges with long term use and marginal improvements in overall survival ${ }^{3}$. Discovery of new and safer angiogenic targets is thus critical.

TGF $\beta$ family members, particularly BMP9 and TGF $\beta$, are the most examined regulators of angiogenesis but have not been effective as targets for angiogenic therapy due to their pleiotropic functions in cancer and normal physiology 4,5 . Similar to TGF $\beta$ and BMP9, activins' have controversial and context dependent roles for regulating angiogenesis. Specifically activin A has been shown to increase VEGF induced angiogenesis in some instances ${ }^{6}$ and in others has been demonstrated to inhibit angiogenesis ${ }^{7}$. Inhibins' are a distinct and unique member of the TGF $\beta$ family as the only endocrine hormone and a functional heterodimer of an alpha (a) subunit (INHA) and a beta ( $\beta$ ) activin subunit (INHBA or INHBB) forming either inhibin $A$ or inhibin $B$ respectively ${ }^{8}$. Inhibins' are distinct from activins which are comprised of homodimers of either beta subunit ${ }^{8}$. Inhibina is synthesized as a pro-peptide with a pro-domain, aN region, and $\mathrm{aC}$ region. The pro-domain and $\mathrm{aN}$ region can be cleaved to produce the mature Inhibina subunit comprising the $\mathrm{aC}$ region. Physiological Inhibina production by the sertoli cells of the testes, granulosa cells of the ovary, and the adrenal and pituitary glands ${ }^{9}$ is regulated primarily by FSH and $\mathrm{LH}^{10,11}$ via a cAMP-PKA pathway resulting in CAMP response element binding (CREB) to the CAMP response element (CRE) on the INHA promoter ${ }^{12}$. 
While inhibin levels (inhibin A and B) cycle across the lifespan of healthy females and dramatically decrease at the onset of menopause ${ }^{13}$, elevated inhibina levels are found in ovarian, gastric, hepatocellular, and prostate cancers ${ }^{14-17}$. Total inhibin levels comprising free inhibina, inhibin $A$ and inhibin $B$ are also an established diagnostic marker alone and/or in combination with CA125, for ovarian cancers $^{18}$ and have been proposed as a potential tumor specific target for therapy, $8,17,19,20$. Inhibina levels are also predictive of survival in multiple cancer types with gene signatures that correlate with INHA expression, providing a highly accurate prognostic model for predicting patient outcomes ${ }^{20}$. However, the mechanism of inhibin expression in cancers have not been delineated.

Hypoxia is a key mediator of angiogenic responses, regulating pro-and anti-angiogenic genes impacting tumor growth, metastasis, and immune evasion ${ }^{21}$ and is driven by the hypoxia inducible factor (HIF) family of transcription factors. Hypoxia induced changes, specifically in tumors, are characterized by inefficient oxygen delivery, leading to leaky vessels and altered permeability, build-up of fluid and ascites in ovarian cancer, and metastasis by facilitating intra/extravasation of tumor cells $\mathrm{s}^{21,22}$. We previously reported decreased ascites accumulation in mice bearing tumor cells with INHA knockdown ${ }^{19}$, indicating a potential role for inhibin in regulating metastasis and vascular functions, a key contributing factor to ascites accumulation. Moreover, inhibin secreted by tumor cells induces angiogenesis via SMAD1/5 signaling in endothelial cells in a paracrine manner dependent on the type III TGF $\beta$ receptor endoglin/CD105 and the type I TGF $\beta$ receptor ALK1 ${ }^{19}$.

To precisely delineate inhibin's significance in cancer and mechanism of action, we now determine the impact of hypoxia, a key mediator of the angiogenic and metastatic response in cancer ${ }^{21}$, and the contribution of inhibin to the hypoxia adaptive response. We discover that hypoxia in ovarian xenograft tumors, cancer cells, and patient samples leads to an increase in inhibin synthesis in a hypoxia inducible factor (HIF) dependent manner. We find that hypoxia induced tumor growth and vascular permeability in vivo is driven by inhibin. Moreover, intervention using an antibody based therapeutic strategy to inhibin can suppress hypoxia driven tumor biology. Mechanistically, inhibin promotes vascular permeability via endoglin and ALK1. Notably, we also describe for the first time using sensitive biophysical methods the nature and stability of the endoglin and ALK1 interaction at the cell surface in response to inhibin. Our findings not just strongly implicate inhibins as part of the hypoxia adaptive response, but also suggest anti-inhibins' as an alternative or companion to current anti- angiogenic therapies that may not be well tolerated.

\section{Materials And Methods}

\section{Cell Lines and Reagents:}

Ovarian epithelial carcinoma cell lines were obtained as described in resource Table 1 and were from ATCC, the NCl cell line repository through an MTA, or were as indicated. Cell line authentication was performed at the Heflin Center for Genomic Science Core Laboratories at UAB. HMEC-1s were grown per 
ATCC instructions. COS7 cells were grown in Dublecco's modified Eagle's medium with 10\% FBS, $100 \mathrm{U}$ penicillin/streptomycin and L-glutamine. Mouse embryonic endothelial cells (MEEC) WT and ENG -/- were grown as previously described ${ }^{23}$. Epithelial carcinoma cell lines HEY, OVCA420, SKOV3 and PA1 were cultured in RPMI-1640 containing L-glutamine, $10 \%$ FBS and $100 \mathrm{U}$ of penicillin-streptomycin ${ }^{24}$. OVCAR-5 and HEK293 were cultured in DMEM containing 10\% FBS and 100U of penicillin streptomycin. ID8ip2Luc was a kind gift from Jill Slack-Davis ${ }^{25}$ and cultured in DMEM containing $4 \% \mathrm{FBS}, 100 \mathrm{U}$ of penicillin streptomycin, $5 \mu \mathrm{g} / \mathrm{mL}$ of insulin, $5 \mu \mathrm{g} / \mathrm{mL}$ of transferrin, and $5 \mathrm{ng} / \mathrm{mL}$ of sodium selenite. All cell lines were maintained at $37^{\circ} \mathrm{C}$ in a humidified incubator at $5 \% \mathrm{CO}_{2}$, routinely checked for myco-plasma and experiments were conducted within 3-6 passages depending on the cell line. For hypoxia experiments, a ProOx Model $\mathrm{C} 21$ was used and set to $0.2 \% \mathrm{O}_{2}$ and $5 \% \mathrm{CO}_{2}$. Anti-inhibin PO/23 and R1 antibodies were obtained from Oxford-Brookes university through an MTA and from Biocare Medical. INHA luciferase construct was generated through restriction cloning into pGL4.10 luciferase plasmid. Primers were designed to 547 base pairs of the INHA promoter containing the first HRE site with Nhe1 and Xho1 restriction sites on the ends. Insert was amplified from PA1 genomic DNA. Insert was ligated into pGL4.10 plasmid with T4 DNA ligase and INHA promoter region was verified through Sanger sequencing. Additional details on resource is provided in Table 1. 
Table 1

\begin{tabular}{|c|c|c|}
\hline RESOURCE & SOURCE & IDENTIFIER \\
\hline & Cell Lines & \\
\hline HMEC-1 & ATCC & CRL-3243 \\
\hline HEK293 & ATCC & CRL-1573 \\
\hline OV-90 & ATCC & CRL-11732 \\
\hline OVCAR-5 & $\mathrm{NCl}-60$ & N/A \\
\hline PA1 & ATCC & CRL-1572 \\
\hline SKOV3 & $\mathrm{NCl}-60$ & N/A \\
\hline OVCA420 & Susan Murphy & $\mathrm{N} / \mathrm{A}$ \\
\hline ID8ip2Luc & Jill Slack-Davis & $\mathrm{N} / \mathrm{A}$ \\
\hline HEY & Susan Murphy & N/A \\
\hline MEEC WT/ENG -/- & Michelle Letarte & N/A \\
\hline \multirow[t]{2}{*}{ cos7 } & ATCC & CRL-1651 \\
\hline & Antibodies & \\
\hline p-MLC2 & Cell Signaling Technologies & \#3671S, AB_330248 \\
\hline HIF-1a & Cell Signaling Technologies & \#14179, AB_2622225 \\
\hline HIF-1a (ChIP grade) & Cell Signaling Technologies & \#3716, AB_2116962 \\
\hline HIF-2a & Cell Signaling Technologies & \#59973, AB_2799579 \\
\hline Normal Rabbit IgG & Cell Signaling Technologies & \#2729, AB_1031062 \\
\hline CD-31 & Cell Signaling Technologies & \#77699, AB_2722705 \\
\hline Vinculin & Santa Cruz & Sc-73264, AB_1131292 \\
\hline Inhibina (R1) & Biocare Medical & SKU171 \\
\hline Anti-inhibin P023 & Oxford Brookes University & \\
\hline Anti-inhibin R1 & Oxford Brookes University & AB_2857371 \\
\hline TRC-105 & Tracon Pharmaceuticals & \#754227 \\
\hline VE-cadherin (for IF) & BD BioSciences & \#610252, AB_2276073 \\
\hline Goat y-globulin (NGG) & Jackson ImmunoResearch & \#005-000-002, AB_2336984 \\
\hline Murine IgG anti-myc tag, 9E10 & BioLegend & \#626802, AB_2148451 \\
\hline
\end{tabular}




\begin{tabular}{|c|c|c|}
\hline RESOURCE & SOURCE & IDENTIFIER \\
\hline Chicken IgY anti-myc tag & Merck Millipore & \#AB3252, AB_2235702 \\
\hline Rabbit IgG anti HA tag, HA.11 & BioLegend & \#902302, AB_2565019 \\
\hline Murine IgG anti-HA tag, 12CA5 & Roche Diagnostics & \#11666606001, AB_514506 \\
\hline Alexa 488-goat IgG anti rabbit IgG & Invitrogen-Molecular Probes & \#R37116, AB_2556544 \\
\hline Alexa 546-goat $\left(\mathrm{Fab}^{\prime}\right)_{2}$ anti mouse lgG & Invitrogen-Molecular Probes & \#A-11018, AB_2534085 \\
\hline Alexa 488-goat $\left(\mathrm{Fab}^{\prime}\right)_{2}$ anti rabbit IgG & Invitrogen-Molecular Probes & \#A-11070, AB_142134 \\
\hline FITC-donkey IgG anti chicken IgY & Jackson ImmunoResearch & \#703-095-155, AB_2340356 \\
\hline \multirow[t]{2}{*}{ Cy3-donkey $\left(\mathrm{Fab}^{\prime}\right)_{2}$ anti mouse IgG } & Jackson ImmunoResearch & \# 715-166-150, AB_2340816 \\
\hline & Reagent & \\
\hline Cobalt Chloride $\left(\mathrm{CoCl}_{2}\right)$ & VWR & \#IC19510725 \\
\hline Recombinant inhibin A & R\&D Systems & \#8506-AB \\
\hline Recombinant VEGF A & R\&D Systems & 293-VE-010 \\
\hline ALK1-Fc & R\&D Systems & \#370-AL \\
\hline Total inhibin ELISA & Ansh Labs & \#AL-134 \\
\hline DynaBeads & Thermo Fisher & \#10003D \\
\hline Lipofectamine 3000 & Thermo Fisher & \#L3000001 \\
\hline TransIT-LT1 Mir2300 & Mirus Bio & \#MIR 2305 \\
\hline RNAiMax & Thermo Fisher & $\# 13778030$ \\
\hline Rhodamine Dextran 70,000 MW & Thermo Fisher & \#D1841 \\
\hline FITC-Dextran 30,000 MW & Thermo Fisher & \#D3306 \\
\hline EZ-Link Sulfo-NHS-SS-Biotin & Thermo Fisher & \#21331 \\
\hline Neutravidin Resin & Thermo Fisher & \#29200 \\
\hline $\begin{array}{l}\text { iScript Reverse Transcription } \\
\text { Supermix }\end{array}$ & BioRad & \#1708841 \\
\hline iTaq Universal SYBR Green Supermix & Biorad & $\# 1725125$ \\
\hline Dual Luciferase Assay System & Promega & \#E1910 \\
\hline Matri-gel & Corning & \#354230 \\
\hline Fibronectin & Cultrex & \#342000101 \\
\hline
\end{tabular}




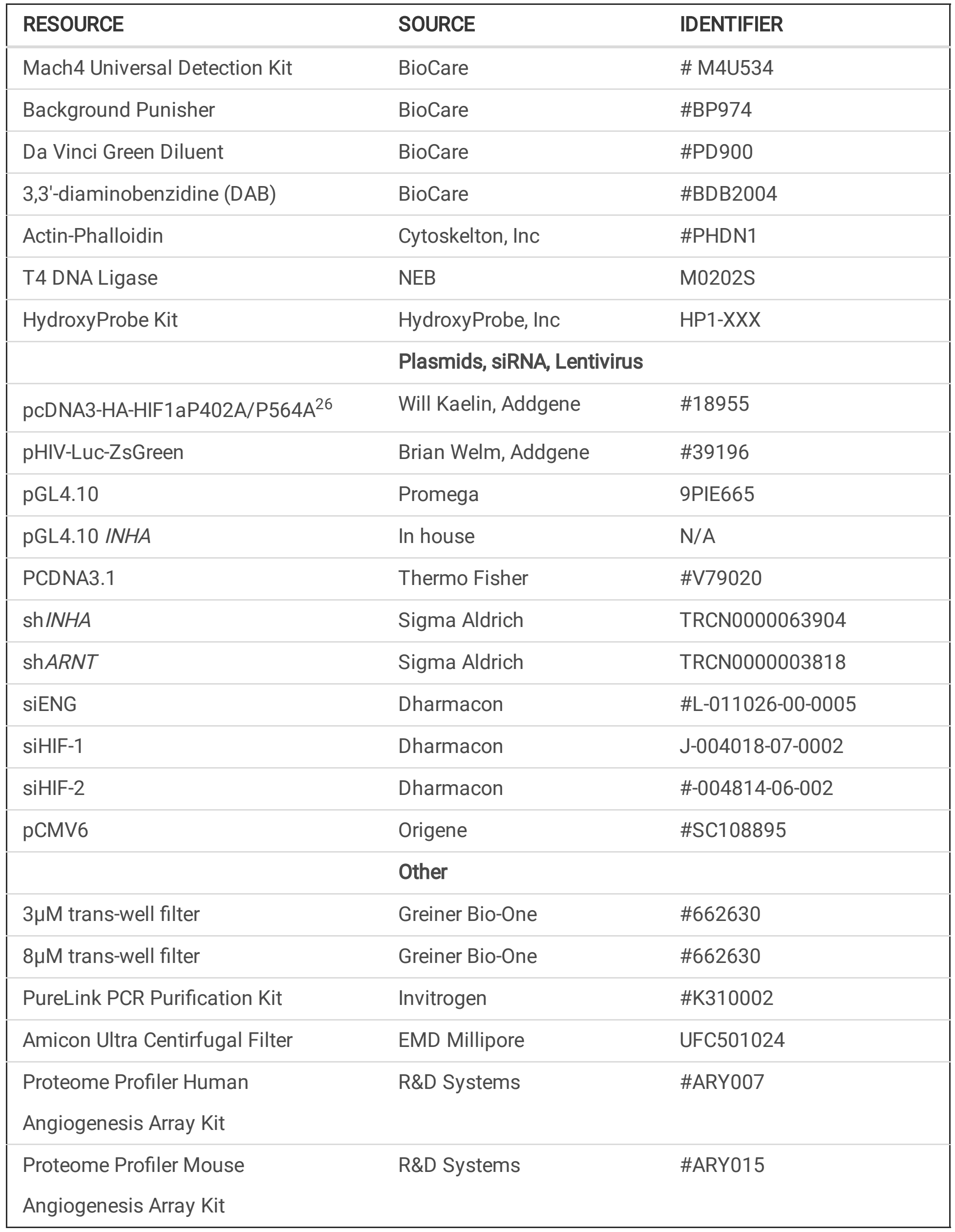




\section{Generation of cell lines}

INHA and $A R N T$ knockdown were generated in HEY cells infected with shRNA lentivirus, followed by selection in $2.5 \mu \mathrm{g} / \mathrm{ml}$ Puromycin and stable cell lines maintained in $1 \mu \mathrm{g} / \mathrm{ml}$ Puromycin. Luc/GFP cell lines were generated using pHIV-Luc-ZsGreen construct. Transient DNA transfections in HEK293 were performed using Lipofectamine 3000. siRNA transfections were performed using RNAiMax. Lentiviral particles were generated at the Center for Targeted Therapeutics Core Facility at the University of South Carolina. shRNA and siRNA sequences are listed in Table 2.

Table 2

\begin{tabular}{|llll|}
\hline Target & Source & Identifier & Target Sequence \\
\hline sh/NHA & Sigma Aldrich & TRCN0000063904 & CCTCGGATGGAGGTTACTCTT \\
shARNT & Sigma Aldrich & TRCN0000003818 & CATTGTCCAGAGGGCTATTAA \\
siHIF-1 & Dharmacon & J-004018-07-0002 & GAACAAAUACAUGGGAUUA \\
siHIF-2 & Dharmacon & J-004814-06-002 & GGCAGCACCUCACAUUUGA \\
\hline
\end{tabular}

\section{RNA Isolation and RT-qPCR}

Total RNA was harvested using Trizol/Chloroform extraction. RNA was transcribed using iScript Reverse Transcription Supermix and iTaq Universal SYBR Green Supermix. Expression data was normalized to RPL13A. qRT-PCR primer sequences are listed in resource Table 3. 
Table 3

\begin{tabular}{|lll|}
\hline Primers & Forward & Reverse \\
\hline Human & & \\
\hline RPL13A & AGATGGCGGAGGTGCAG & GGCCCAGCAGTACCTGTTTA \\
\hline INHA & CGCTCAACTCCCCTGATGTC & GGGTACACGATCCACCGTTC \\
\hline ENG & CGCCAACCACAACATGCAG & GCTCCACGAAGGATGCCAC \\
\hline TGFBR3 & GCCATCCAATCGAGACCCTG & TGATTGTTGGACTCCTCAGTG \\
\hline INHBA & GAACGGGTATGTGGAGATAGAG & TGTTCCTGACTCGGCAAA \\
\hline INHBB & GCGCGTTTCCGAAATCATCA & AGGTTCTGGTTGCCTTCGTT \\
\hline ARNT & TGACTCCTGTTTTGAACCAGC & CTGCTCACGAAGTTTATCCACAT \\
\hline Mouse & & \\
\hline RPL13A & CAAGGTTGTTCGGCTGAAGC & GCTGTCACTGCCTGGTACTT \\
\hline INHA & AGGAAGATGTCTCCCAGGCT & GTTGGGATGGCCGGAATACA \\
\hline ChIP Primers & & \\
\hline INHA HRE 1 & GGGATGTTCAGGTCCATCAG & CACACTGTAGTTGTGCAGTCAA \\
\hline INHA HRE 2 & CCTCGTTCACCCAGAAGGTC & GATTCCGGCGTCTACGTGTG \\
\hline
\end{tabular}

\section{ELISA}

Total inhibin ELISA's were performed according to the manufacturer's instructions for the quantitative measurement of Total inhibin (Inhibin A, Inhibin B, and free Inhibin alpha subunit) from conditioned media of tumor cells. Cells were grown to $80 \%$ confluency in 24 well plates before media was replaced with fresh full serum media. Cells were placed in hypoxia chamber for $24 \mathrm{hrs}$ and media was collected and concentrated using Amicon Ultra centrifugal filter.

\section{IN VITRO ASSAYS}

In vitro Permeability Assay was adapted from Martins-Greene ${ }^{27} .1 \times 10^{5}$ HMEC- 1 cells were plated onto a Matrigel coated $3 \mu \mathrm{M}$ trans-well filter in full serum media. After $24 \mathrm{~h}$ hours, a second layer of $1 \times 10^{5} \mathrm{HMEC}$ 1 was plated on top to obtain a confluent monolayer of cells. After an additional $24 \mathrm{hrs}$, media was replaced with serum free media in the top of the trans-well and either conditioned media (with $2 \mu \mathrm{g}$ of either $\mathrm{R} 1, \mathrm{PO} / 23$, or $\mathrm{IgG}$ ) or serum free media containing growth factor in the bottom chamber as indicated in legends. FITC-dextran was added to the lower chamber $(10 \mu \mathrm{g} / \mathrm{ml})$. At indicated time points $10 \mu \mathrm{L}$ aliquots were taken from the top chamber in triplicate and measured using microplate reader for 
FITC-dextran passage. At end point, filters were stained with crystal violet to confirm equal monolayers were achieved.

Trans-well Migration Assay: 75000 HMEC-1 were plated on a fibronectin coated $(10 \mu \mathrm{g} / \mathrm{mL}) 8 \mu \mathrm{M}$ transwell filter in serum free media. Conditioned media (with $2 \mu \mathrm{g}$ of either $\mathrm{R} 1, \mathrm{PO} / 23$, or $\lg \mathrm{G}$ ) or serum free media containing $1 \mathrm{nM}$ inhibin A or VEGF A was used as a chemoattractant in the bottom chamber. After $24 \mathrm{hrs}$, unmigrated cells were scraped off the apical side, migrated cells were fixed in methanol:acetic acid, and nuclei were stained with Hoechst. Three random images were taken per filter using 10X objective on EVOS M7000 microscope. Nuclei were counted using ImageJ.

\section{Trans-endothelial Migration Assay}

HMEC-1 were grown on $8 \mu \mathrm{m}$ trans-well filters as per permeability assay. HMEC-1 monolayer was treated with $1 \mathrm{nM}$ inhibin A or untreated for four hours. After four hours of treatment, 150000 HEY-LucGFP expressing cells were plated on top of the HMEC- 1 monolayer and allowed to invade for $18 \mathrm{hrs}$. Filters were fixed in $4 \%$ paraformaldehyde, cells on the apical side of the filter were scraped off, and filters were mounted on glass slides for imaging. Migration of $\mathrm{GFP}^{+}$cells was visualized using 10x objective on EVOS M7000 microscope. Three random fields were captured per filter and GFP ${ }^{+}$cells were counted using ImageJ software. Thresholding, circularity and size gating were used to exclude unmigrated cells and artifacts.

Chromatin Immunoprecipitation protocol was adapted from ABCAM. Briefly, OV-90 or OVCAR- 5 cells were grown in $150 \mathrm{~cm}^{2}$ dishes until $80 \%$ confluency was reached. Cells were kept under normoxia or placed in the hypoxia chamber set at $0.2 \% \mathrm{O}_{2}$ for either $12 \mathrm{hrs}$ (OVCAR-5) or $24 \mathrm{hrs}(\mathrm{OV}-90)$. DNA was crosslinked using $0.75 \%$ formaldehyde and sheared by sonication to a fragment sizes between $100-400 \mathrm{bp}$. DNA was immunoprecipitated with Dyna-beads and either HIF-1a antibody or Normal Rabbit IgG as a control. DNA was purified using Purelink PCR Purification kit and amplified using RT-qPCR with ChIP primers.

\section{Luciferase Assay}

HEK293 cells were seeded into 24 well plate and co-transfected with a luciferase reporter containing 547 base pairs of the INHA promoter (pGL4.10 INHA) and a SV40 (Renilla internal control vector). For HIF-1 overexpression, cells were also co-transfected with pcDNA3-HA-HIF1aP402A/P564A or PCDNA3.1. One day after transfection, cells were left in a normoxia incubator or moved to hypoxia chamber $\left(0.2 \% \mathrm{O}_{2}\right)$ for 24hrs. Luciferase activity was measured using the Dual Luciferase Reporter Assay System by calculating the ratio between luciferase and Renilla and normalized to normoxia or PCDNA3.1 as indicated in legends.

\section{Immunofluorescence}

HMEC-1 cells were grown to confluence on fibronectin $(10 \mu \mathrm{g} / \mathrm{mL})$ and treated with either $1 \mathrm{nM}$ inhibin A or VEGF A for 30 minutes in serum free media. Cells were fixed in $4 \%$ paraformaldehyde and permeabilized 
with $0.2 \%$ TritonX-100, followed by blocking with $5 \%$ BSA in PBS for $1 \mathrm{hr}$. VE-cadherin was labeled with anti-VE-cadherin antibody overnight at $4^{\circ} \mathrm{C}$ followed by AlexaFluor 488 secondary antibody. F-actin was stained with rhodamine-phalloidin and nuclei were labeled with DAPI. Immunofluorescence imaging was performed on EVOS M7000 microscope or Nikon A1 confocal microscope. Actin fibers were quantified by measuring anisotropy using the FibrilTool Plugin in Image $\mathrm{J}^{28}$.

\section{VE-cadherin Internalization}

HMEC-1 cells grown to confluence on fibronectin $(10 \mu \mathrm{g} / \mathrm{mL})$ coated glass coverslips. Cell surface VEcadherin was labeled with anti-VE-cadherin antibody at $4^{\circ} \mathrm{C}$ for 30 minutes, washed with ice-cold PBS, and incubated at $37^{\circ} \mathrm{C}$ for 30 minutes with $1 \mathrm{nM}$ inhibin $\mathrm{A}, 1 \mathrm{nM}$ VEGF A, or serum free media. After internalization was stimulated with growth factor at $37^{\circ} \mathrm{C}$, anti-VE-cadherin antibody on the cell surface was removed with mild acid wash. Internalized VE-cadherin was visualized by immunofluorescence microscopy. Internalized VE-cadherin was quantified using BlobFinder software ${ }^{29,30}$. Nuclei and cytoplasm were delineated and the number of signals per cell was used to quantify internalized VEcadherin fluorescence.

\section{Cell Surface Biotinylation}

Briefly, MEEC WT or /ENG-/- were grown to confluence on gelatin coated dishes. Cell surface proteins were labeled with $2 \mathrm{mg} / \mathrm{mL}$ Sulfo-NH-SS biotin for $30 \mathrm{~min}$ at $4^{\circ} \mathrm{C}$. After labeling, cells were treated with $1 \mathrm{nM}$ inhibin $\mathrm{A}$ or untreated in serum free media for $30 \mathrm{~min}$ at $37^{\circ} \mathrm{C}$ or left at $4^{\circ} \mathrm{C}$ for cell surface control samples. After treatment, cell surface biotin was removed with 20mM MESNA buffer and internalized biotin labeled protein was isolated with neutravidin resin. Internalized biotin labeled VE-cadherin was detected by Western Blot.

\section{Epitope-tagged plasmids and transfection of COS7 cells for patch/FRAP studies}

The following plasmids were donated by Prof. G. C. Blobe, Duke University Medical Center: HA-tagged endoglin (endoglin-L) in pDisplay, myc-endoglin generated by PCR incorporation of the myc tag sequence into untagged endoglin in pDisplay and re-cloned in pcDNA3.1, and HA- or myc-tagged ALK1 in pcDNA3. ${ }^{31}$. Human ALK4 with C-terminal myc-DDK tags in pCMV6 was obtained from OriGene Technologies (Rockville, MD), and subcloned into pcDNA3.1 by PCR followed by restriction digest and religation. A stop codon was introduced at nucleotide 1516 to delete the $\mathrm{C}$-terminal tags to generate untagged ALK4. This was followed by insertion of N-terminal HA tag by overlapping PCR after nucleotide 72 to generate extracellularly tagged HA-ALK4. All constructs were verified by sequencing. COS7 cells were transfected using TransIT-LT1 Mir2300 according to manufacturer's instructions. For Patch/FRAP experiments, cells grown on glass coverslips in 6-wells plates were transfected with different combinations of these vectors encoding myc- and/or HA-tagged receptor constructs. The amounts of the 
vectors (between 0.5 and $1 \mu \mathrm{g}$ DNA) were adjusted to yield similar cell surface expression levels, determined by quantitative immunofluorescence.

\section{Fluorescent antibody labeling and IgG-mediated cross- linking for patch/FRAP}

COS7 cells were transfected with various combinations of the above epitope-tagged expression vectors. After $24 \mathrm{~h}$, The cells were serum-starved (1\% FBS, 30 min, $\left.37^{\circ} \mathrm{C}\right)$, washed with cold Hank's balanced salt solution (HBSS containing 20 mM HEPES, pH 7.2) and 2\% BSA (HBSS/HEPES/BSA), and blocked with normal goat $\mathrm{y}$-globulin $\left(200 \mu \mathrm{g} / \mathrm{ml}, 30 \mathrm{~min}, 4^{\circ} \mathrm{C}\right)$. For FRAP studies on singly-expressed receptors, the cells were then labeled successively at $4^{\circ} \mathrm{C}$ in HBSS/HEPES/BSA (45 min incubations) with: (i) monovalent murine Fab' anti myc tag (amyc) or anti HA tag ( $\mathrm{aHA} ; 40 \mu \mathrm{g} / \mathrm{ml})$, prepared from the respective IgGs as described by us earlier ${ }^{32}$; (ii) Alexa 546-Fab' goat anti mouse (GaM; $\left.40 \mu \mathrm{g} / \mathrm{ml}\right)$, prepared from the respective $F\left(a b^{\prime}\right)_{2}$ as described ${ }^{33}$. For patch/FRAP studies, they were labeled by one of two protocols. Protocol 1 employed successive labeling with: (i) monovalent mouse Fab' amyc (40 $\mu \mathrm{g} / \mathrm{ml})$, alone or together with HA.11 rabbit aHA IgG $(20 \mu \mathrm{g} / \mathrm{ml})$ and (ii) Alexa 546-Fab' GaM $(40 \mu \mathrm{g} / \mathrm{ml})$ alone or together with Alexa 488-IgG goat anti rabbit (GaR; $20 \mu \mathrm{g} / \mathrm{ml})$. This protocol results in the HA-tagged receptor crosslinked and immobilized by IgGs, whereas the myc-tagged receptor, whose lateral diffusion is then measured by FRAP, is labeled exclusively by monovalent Fab'. Alternatively, we employed protocol 2 for immobilizing the myc-tagged receptor and measuring the lateral diffusion of a co-expressed Fab'-labeled HA-tagged receptor: (i) monovalent mouse Fab' aHA $(40 \mu \mathrm{g} / \mathrm{ml})$ together with chicken IgY amyc (20 $\mu \mathrm{g} / \mathrm{ml}$ ) and (ii) Cy3-Fab' donkey anti mouse (DaM; $40 \mu \mathrm{g} / \mathrm{ml}$ ) together with FITC-IgG donkey anti chicken $(\mathrm{DaC} ; 20 \mu \mathrm{g} / \mathrm{ml})$. In experiments with inhibin A, the ligand was added after starvation along with the normal goat $\mathrm{Y}$-globulin and maintained at the same concentration throughout the labeling steps and FRAP measurements.

\section{FRAP and patch/FRAP}

COS7 cells co-expressing epitope-tagged receptors labeled fluorescently by anti-tag Fab' fragments as described above were subjected to FRAP or patch/FRAP experiments as described ${ }^{34}$. FRAP studies were conducted at $15^{\circ} \mathrm{C}$, replacing samples after 20 min to minimize internalization. An argon-ion laser beam (Innova 70C, Coherent, Santa Clara, CA) was focused through a fluorescence microscope (Axioimager.D1; Carl Zeiss Microlmaging, Jena, Germany) to a Gaussian spot of $0.77 \pm 0.03 \mu \mathrm{m}$ (Planapochromat $63 x / 1.4$ NA oil-immersion objective). After a brief measurement at monitoring intensity $(528.7 \mathrm{~nm}, 1 \mu \mathrm{W})$, a $5 \mathrm{~mW}$ pulse $(20 \mathrm{~ms})$ bleached $60-75 \%$ of the fluorescence in the illuminated region, and fluorescence recovery was followed by the monitoring beam. Values of $D$ and $R_{f}$ were extracted from the FRAP curves by nonlinear regression analysis, fitting to a lateral diffusion process ${ }^{34}$. Patch/FRAP studies were conducted analogously, except that IgG-mediated cross-linking of epitope-tagged endoglin preceded the measurement ${ }^{34}$.

\section{Patient Ascites}


Specimens from patients diagnosed with primary ovarian cancer was collected and banked after informed consent at Duke University Medical Center, with approval for the study from Duke University's institutional research ethics board. ELISA's were conducted using ELISA for Total inhibin from Ansh labs (\#AL-134).

\section{Public Data Mining}

Clinical data and normalized RNA-seq were obtained from cBioportal ${ }^{35}$. The ovarian serous cystadenocarcinoma (TCGA, PanCancer Atlas) and breast invasive carcinoma (TCGA, PanCancer Atlas) were assessed for INHA expression and hypoxia (Buffa or Winter) scores. INHA expression was plotted against hypoxia score for each patient for correlation analysis.

IN VIVOASSAYS. All animal studies and mouse procedures were conducted in accordance with ethical procedures after approval by UAB's IACUC prior to study commencement.

\section{Matri-gel Plug Assay}

Matrigel plugs were formed using $200 \mu \mathrm{L}$ of Matrigel mixed with $50 \mu \mathrm{L}$ of HEY conditioned media and injected subcutaneously into the underside of BALB/c female mice aged 5-6 weeks. For conditioned media, HEY cells were grown until $80 \%$ confluence in 24 well plate before media was replaced with fresh full serum media. Cells were placed in hypoxia chamber for $24 \mathrm{hrs}$ and media was collected and concentrated to $50 \mu \mathrm{L}$ Savant SpeedVac SPD1030. Conditioned media was incubated with $2 \mu \mathrm{g}$ of either $\mathrm{R} 1$ or IgG overnight before injection. Plugs were harvested 12 days after injection and hemoglobin content was determined according to Drabkin's method ${ }^{19}$.

\section{In vivo subcutaneous tumor growth and permeability analysis}

$3 \times 10^{6} \mathrm{HEY}$ cells either exposed to normoxia or hypoxia $\left(0.2 \% \mathrm{O}_{2}\right)$ for $24 \mathrm{hrs}$ were subcutaneously injected into right flank of 6-week old Ncr Nude mice (Taconic). Tumor volume (( $\left.\left.\mathrm{LWW}^{2}\right) / 2\right)$ was calculated by caliper measurements every other day starting at day 10 until harvest at day 30 . In animals receiving antiinhibin treatment, R1 (BioCare) was administered IP at 2mg/kg three times weekly. Da Vinci Green diluent (BioCare) was administered as vehicle.

For measurement of permeability, tumors were harvested between $700-800 \mathrm{~mm}^{3}$. At end point, Rhodamine Dextran $70000 \mathrm{MW}$ was intravenously injected at $2 \mathrm{mg} / \mathrm{kg}$ two hours before euthanasia. Tumors were fixed in 10\% NBF and sections were analyzed for rhodamine-dextran by immunofluorescence on EVOS M7000. Three sections per tumor were quantified and four images per section were taken. Thresholding was performed in Image J and kept constant for all images. ROUT analysis $(Q=10 \%)$ was performed to test for outliers.

For tumor hypoxia analysis, tumors were harvested at varying sizes between $200-1400 \mathrm{~mm}^{3}$. Pimonidazole (HydroxyProbe) was injected intravenously at $60 \mathrm{mg} / \mathrm{kg} 1 \mathrm{hr}$ before sacrifice. Tumors were 
fixed in 10\% NBF and sections were analyzed for pimonidazole adducts using anti-pimonidazole monoclonal antibody.

Immunofluorescence on Tissues: Briefly, formalin fixed, paraffin-embedded tissues from subcutaneous tumors were deparaffinized by sequential washing with xylene, $100 \%$ ethanol, $90 \%$ ethanol, $70 \%$ ethanol and distilled water for 10 min each. Antigen retrieval was performed by boiling tissues in sodium citrate buffer ( $\mathrm{pH}$ 6.0). Blocking was performed with Background Punisher. Primary antibodies, antipimonidazole (1:50) and anti-CD-31(1:100), were diluted in Da Vinci Green Diluent and incubated overnight at $4^{\circ} \mathrm{C}$ in a humidified chamber followed by AlexaFluor 594 secondary antibody. Nuclei were stained with DAPI. 10x images were acquired on EVOS M7000 microscope.

Quantitation of CD-31 labeled vessel size and number as well as pimonidazole was performed in ImageJ. Images were converted to binary and thresholding mask was applied equally to all images. For CD-31, objects smaller than 25 pixels were removed as were deemed too small to be vessels. For each image, average vessel size (area) and average vessel number was measured. Four images per section and two sections per tumor were used for quantitation. For pimonidazole, a 10x stitched image comprising the whole tumor section was used. The total area covered by signal was acquired and divided by total tumor area to calculate the \% hypoxic area for each tumor.

Angiogenesis Proteome Array was performed according to manufacturer's instruction (R\&D Systems, Table 1). Briefly, tissues were homogenized in PBS with 1\% TritonX-100 and PI cocktail. $200 \mu \mathrm{g}$ of protein was used per sample (two samples for shControl and sh INHA tumors each). Pixel intensity was quantified for each dot using ImageStudio software after background subtraction.

\section{Statistical Analysis}

All data are representative of three independent experiments, unless otherwise described in legends. Statistical analyses were performed using GraphPad Prism 9, with statistical test chosen based on experimental set up and specifically described in the figure legends. Data are expressed as mean \pm SEM. Difference between two groups was assessed using a two-tailed t-test. Multiple group comparisons were carried by the analysis of variance (ANOVA) using One or Two-way ANOVA followed by appropriate posthoc tests as indicated in Figure legends.

\section{Results}

Expression and secretion of inhibin is regulated by hypoxia in ovarian xenograft tumors cell lines and in patients

We and others have previously demonstrated increased expression of inhibina mRNA and protein in a broad spectrum of cancers leading to increased angiogenesis in vitro and in vivo impacting metastasis ${ }^{17,19,36}$. Based on the potential role of inhibins' in cancer angiogenesis, we tested the impact of hypoxia, a key regulator of angiogenesis, on INHA expression. A panel of ovarian cancer cell lines 
representing a broad spectrum of ovarian cancer subtypes, including HEY, OV90, OVCAR5 of high grade serous origin, PA1 a teratocarcinoma cell line of the ovary, and ID8ip2 a mouse ovarian cancer cell line, were grown for twelve or twenty-four hours under either hypoxic conditions $\left(0.2 \% \mathrm{O}_{2}\right)$ or normoxic control tissue culture conditions (17-21\%). Changes to INHA were evaluated by semi quantitative RT-PCR with VEGFA as a positive control (Fig. 1Ai-ii). We find a 3-6 times increase in INHA expression across all four cell lines (HEY: 4.87-times, OVCAR5: 4.4-times, PA1: 5.28, OV90: 3.1-times, ID8ip2: 4-times, Fig. 1 Ai). All cell lines showed maximum INHA increases after $24 \mathrm{hrs}$ of hypoxia growth except for OVCAR5 which increased INHA expression within $12 \mathrm{hrs}$ under hypoxia. VEGFA was evaluated side by side as a positive control and representative of the hypoxia response ${ }^{37}$ in all four cell lines and was elevated 2-6-times (HEY: 3.5-times, OVCAR5: 3.1-times, PA1: 5.18-times, OV90: 2.5-times, Fig. 1Aii). HIF-1a stabilization in all cell lines confirmed by westerns indicated an active response to hypoxia in indicated cell lines (Fig. 1 Aiii).

INHA translates into the protein inhibina which can be secreted as a free monomer or can dimerize with INHBA or INHBB to produce dimeric functional inhibin A or inhibin $\mathrm{B}^{12}$. Thus, total inhibin ELISA, which detects all three, was used to test if the changes in INHA mRNA resulted in alterations to secreted protein. We find that conditioned media collected from HEY and OV90 exposed to hypoxia increased total inhibin protein secretion as well, (4.2-times in HEY and 3.8-times OV90, Fig. 1B). These data suggest that INHA mRNA and functional secreted inhibin protein, is increased by hypoxia.

Since total inhibin protein, reflecting either inhibin A/B and free inhibina, increased in response to hypoxia (Fig. 1B), we evaluated mRNA changes in INHBA and INHBB subunits in HEY and OV90 cells. While INHA was increased three to five-times in response to hypoxia (Fig. 1A), INHBA and INHBB levels were unchanged in the two cell lines evaluated (Fig. 1C), indicating that changes in inhibin protein levels (Fig. 1B) were largely related to increases in inhibina. The INHA response to hypoxia was also more robust in tumor cells as compared to endothelial cells (HMEC- 1 ) grown under hypoxia $\left(0.2 \% \mathrm{O}_{2}\right)$ for $24 \mathrm{hrs}$ exhibited (Supp Fig. 1) indicating that inhibina increases in response to hypoxia occur more significantly in tumor cells.

To evaluate other pathologically relevant hypoxic conditions pertinent to ovarian cancer growth and metastasis, we evaluated hypoxia and INHA expression in cells grown in spheroids under anchorage independence, an environment that is often hypoxic ${ }^{38}$. PA1 and OVCA420 cells were chosen due to their ability to form spheroids ${ }^{39,40}$. Cells were grown on poly-hema coated plates for either 72 hrs (PA1) or 48hrs (OVCA420). Under such 3D conditions, where HIF-1 a was stabilized (Fig. 1Di), INHA was increased 7.8-times in PA1 and 4.6-times in OVCA420 when compared to 2D growth conditions in a dish (Fig. 1Dii).

Previous studies have established that in healthy pre-menopausal women, inhibin levels cycle across the menstrual cycle reaching a peak of $65.6 \mathrm{pg} / \mathrm{mL}$, while in post-menopausal women, total serum inhibin levels are below $5 \mathrm{pg} / \mathrm{mL}^{41}$. Ovarian cancer patients are commonly postmenopausal ${ }^{42}$ and tumor tissues can display higher inhibin levels ${ }^{19}$. We thus wanted to assess if the peritoneal ascites fluid of advanced ovarian cancer patients, which has been shown to be a hypoxic environment ${ }^{43}$ and contains 
disseminated ovarian cancer spheroids ${ }^{22}$, also displays detectable or elevated inhibin levels. To test if inhibin protein is secreted and detectable in clinical ascites, total inhibin ELISA was performed on a cohort of 25 patient ascites (Methods). We find total inhibin levels in the range of 6.7 to $120.53 \mathrm{pg} / \mathrm{mL}$ in the ascites fluid with increasing concentrations found in higher stages of disease (Fig. 1E).

We next evaluated if INHA expression was elevated in vivo with increasing xenograft tumor size. 5 million HEY cells were subcutaneously implanted and harvested at varying tumor sizes. Tumors greater than $500 \mathrm{~mm}^{3}$ were found to be hypoxic based on pimonidazole staining (4.8-times, Fig. 1Fi and Supp Fig. 2A). INHA expression was increased 9.8 times in tumors greater than $500 \mathrm{~mm}^{3}$ than in tumors less than $500 \mathrm{~mm}^{3}$ (Fig. 1Fii). INHA expression was also significantly correlated with tumor size (Supp Fig. 2B). To further examine the potential clinical relevance of inhibina expression in response to hypoxia, we analyzed the TCGA/PanCancer Atlas patient data set from cBioportal ${ }^{35,44}$ and obtained hypoxia scores from two different hypoxia gene signatures (Buffa and Winter) ${ }^{45,46}$. The signatures consisted of 51 (Buffa) and 99 (Winter) hypoxia related genes from a large meta-analysis of breast and head and neck squamous cell cancer that were independently verified for prognostic value ${ }^{45,46}$. Using these signatures, inhibina (INHA) expression was significantly correlated with both hypoxia Buffa $(r=0.1961, p=0.0221)$ and Winter hypoxia $(r=0.223, p=0.009)$ scores in the ovarian cancer data set (Fig. 1Gi-ii). Analysis of breast cancer data revealed a similar trend as INHA expression was significantly correlated $(r=0.2026, p=0.0165)$ with the Buffa hypoxia score (Fig. 1Giii). Taken together, these data strongly indicate that inhibina mRNA and protein expression are increased under hypoxia conditions in ovarian cancer cell lines, xenograft tumors and in patients.

\section{INHA is a direct HIF-1 target under hypoxia}

Hypoxia inducible factors (HIFs) are key transcriptional regulators of the hypoxia adaptive response and increase expression of critical pro-angiogenic genes ${ }^{21}$. To test whether HIF proteins are regulators of INHA expression, we first utilized cobalt chloride $\left(\mathrm{CoCl}_{2}\right)$, a well characterized chemical stabilizer of $\mathrm{HIF}^{47}{ }^{47}$. HIF-1a was stabilized in PA1 and OVCAR5 cells treated with $100 \mu \mathrm{M}$ of $\mathrm{CoCl}_{2}$ for either 6,12 , or 24 hrs (Fig. 2Ai). We find that INHA expression was significantly increased; 10-times in OVCAR5 after $12 \mathrm{hrs}$ and 11.5-times in PA1 cells after 24hrs of $\mathrm{CoCl}_{2}$ treatment (Fig. 2Aii). Maximum increases in INHA expression with $\mathrm{CoCl}_{2}$ occurred at the same time points as exposure to hypoxia (12hrs for OVCAR5 and 24hrs for PA1, Fig. 1 Ai). VEGFA, used as a positive control increased 4.8 and 4.3-times at $12 \mathrm{hrs}$ and 2.7 and 3.7-times at 24hrs in both OVCAR5 and PA1, respectively (Fig. 2Aii). To test if INHA could be a direct hypoxia target leading to increased inhibina expression, we evaluated the effect of reducing the levels of $\mathrm{HIF}-1 \beta / A R N T$ which is the binding partner for all HIF's ${ }^{48}$. Stable ARNT knockdown cells were generated in HEY cells (Methods). We find that control HEY cells increase INHA levels 2.8 -times under $0.2 \%$ hypoxia (Fig. 2B). However, shRNA ARNT lead to a 2.7-times reduction in hypoxia induced increase in INHA mRNA levels (Fig. 2B) indicating direct contributions of HIFs' to the regulation of inhibin. 
To determine the roles of the HIF-1 and HIF-2 heterodimeric transcriptions factors, that both require $\mathrm{ARNT}^{48}$, in the transcriptional regulation of INHA we used siRNA to knockdown the levels of HIF-1a and HIF-2a (Methods). HEK293 cells were used as they express relatively equal levels of both HIF isoforms (Fig. 2Ci). HEK293 cells with either control or HIF1/2a siRNAs were exposed to hypoxia for 24hrs and efficacy of HIF1/2a knockdown was confirmed by immunoblotting (Fig. 2Ci). Notably, siRNA to HIF-1a (siHIF-1a; Fig. 2Cii) decreased hypoxia induced INHA expression 1.8-times as compared to scramble controls (siScr; Fig. 2Cii). However, siRNA to HIF-2a resulted in a smaller (1.25-times) and non-significant reduction in INHA expression compared to siScr when exposed to hypoxia (Fig. 2Cii). These data suggest that increases in INHA under hypoxia were more significantly impacted by HIF-1 as compared to HIF-2 .

In silico, analysis of the INHA gene, which is located at Chr:2q35 revealed two hypoxia response element (HRE) consensus sites within 2Kb of the promoter, GGCGTGG and CGCGTGG, at -144 and -1789 bp from the transcription start site (TSS) (Supp Fig. 3A) respectively. These HRE sites conform precisely to the $(G / C / T)(A / G) C G T G(G / C)$ consensus sequence ${ }^{48}$. Two hypoxia ancillary sequences (HAS) (CAGGG and CACGG) were also found directly flanking the proximal HRE sequence at -169 and -173 bp from the TSS, respectively. One HAS sequence (CACGT) was found flanking the distal HRE sequence at $-1761 \mathrm{bp}$ from TSS (Supp Fig. 3A). A previously well characterized CREB binding site (CRE) is designated for reference (Supp Fig. 3A).

To test direct interactions between HIF-1 and the INHA promoter, chromatin immunoprecipitation (ChIP) was performed using OVCAR5 and OV90 cells. Primers were designed to amplify the region including the HRE site closest to the transcription start site (HRE1) and chromatin shear size optimized accordingly (Methods). We find that exposure to hypoxia led to a 4-times increase in enrichment of HIF-1 binding to INHA's HRE site in OVCAR5 and 3-times in OV90 (Fig. 2D). The second HRE site is GC rich which lead to modest amplification. Despite this, a 2-times increase in HIF-1 enrichment at this site in OV90 cells was observed (Supp Fig. 3B) which was however not statistically significant.

Given the poor enrichment of HIF-1 at the distal promoter site (Fig. S3B), we next evaluated if the proximal promoter was sufficient to increase INHA levels under hypoxia and if this was dependent on HIF1. To achieve this, we utilized 547 base pairs of the INHA promoter, containing the first HRE site (Fig. S3A), in a luciferase reporter assay (Fig. 2E). The effect of HIF-1 on INHA promoter activity, was evaluated in HEK293 cells exposed to hypoxia $\left(0.2 \% \mathrm{O}_{2}\right)$ for $24 \mathrm{hrs}$ and compared to cells under normoxia (Fig. 2Ei), or in the presence or absence of HIF-1 ODD (pcDNA3-HA-HIF1aP402A/P564A) (Fig. 2Eii) that prevents degradation of the HIF1a subunit ${ }^{26}$. We find that in un-transfected or control vector expressing cells (pcDNA3.1), INHA promoter luciferase activity is increased two times in response to hypoxia (Fig. 2Ei) that was mimicked by stabilization of HIF-1a (HIF-1 ODD) under normoxia conditions (Fig. 2Eii). These data point to a central role for HIF-1 in regulating INHA expression under hypoxia.

INHA has been previously reported to be regulated by other factors particularly the cAMP response element binding (CREB) family member in multiple systems ${ }^{8}$. The CREB family of transcription factors can act downstream of the hypoxia response ${ }^{49}$. To thus test whether cAMP was involved in regulating 
INHA expression under hypoxia, we utilized forskolin (Fsk), an activator of cAMP previously shown to induce INHA expression and the PKA inhibitor $\mathrm{H} 89$ previously shown to inhibit forskolin induced INHA expression ${ }^{50}$. Treatment of ID8ip2 cells with Fsk increased INHA expression 5.2-times under hypoxia compared to just 2-times under normoxia (Supp Fig. $3 \mathrm{C}$ ). This relationship appeared to be additive and not synergistic as addition of the PKA inhibitor, $\mathrm{H} 89$, was not able to reduce hypoxia induced INHA expression (Supp Fig. 3 C). Taken together, these data implicate HIF-1 as being the key transcriptional factor responsible for increase of INHA in hypoxia.

\section{Inhibin promotes hypoxia induced angiogenesis and stimulates endothelial cell migration and vascular permeability}

Hypoxia is a key driver of endothelial cell migration and blood vessel permeability within the tumor leading to alterations in angiogenesis ${ }^{37}$. To determine the overall contribution of inhibin to hypoxia induced angiogenesis in vivo, we utilized an in vivo Matrigel plug assay. Conditioned media (CM) from HEY tumor cells exposed to normoxia or hypoxia was used to stimulate angiogenesis into the plugs and a well-established anti-inhibina antibody, R1 (recognizing the junction between the aN region, and aC region) ${ }^{51}$ was used to block inhibin in the $\mathrm{CM}$ with $\mathrm{IgG}$ as a control. We find that $\mathrm{CM}$ from hypoxia grown cells increased hemoglobin in the plugs 2.9-times compared to CM from normoxia grown cells (Fig. 3Aiii). Anti-inhibina in the hypoxic $\mathrm{CM}$ fully reduced the hemoglobin content in the plug (2.1-times suppression, Fig. 3Ai-ii) indicating that inhibin is required for hypoxia induced blood vessel formation in vivo.

Since blood vessel flow is an indication of endothelial cell functionality ${ }^{52}$, we sought to define the specific effects of increased inhibina on hypoxia induced endothelial cell biology, specifically endothelial cell chemotaxis and vascular permeability. To determine the impact on endothelial chemotaxis to hypoxic $\mathrm{CM}, \mathrm{CM}$ from either hypoxia ( $24 \mathrm{hrs}, 0.2 \% \mathrm{O}_{2}$ ) or normoxia grown OV90 or HEY cells were used as a chemoattractant to measure migration of human microvascular endothelial cells (HMEC-1; Fig. 3B). Two anti-inhibina antibodies, R1 and a second well established antibody PO23 (recognizing the C-terminus of the $\mathrm{aC}$ region) ${ }^{51}$, were used with $\mathrm{IgG}$ controls to test the effect of blocking/sequestering hypoxia produced inhibina. We find that $\mathrm{CM}$ from hypoxia grown tumor cells significantly increased migration of endothelial cells (IgG, Fig. 3B) and incubation of hypoxic CM with anti-inhibina R1 significantly suppressed hypoxia induced endothelial migration (2.1 and 1.6-times for OV90 and HEY conditioned media respectively, Fig. 3Bi-ii). Anti-inhibina PO23 was also able to significantly suppress CM stimulated endothelial migration (1.5 and 1.75-times for OV90 and HEY CM, respectively, Fig. 3Bi-ii). Similar to the effects of hypoxic $\mathrm{CM}$, recombinant inhibin $\mathrm{A}$ was also able to stimulate HMEC-1 migration to similar extents as VEGF A at equimolar amounts (Fig. 3Biii).

We next evaluated the effect of $\mathrm{CM}$ from hypoxic tumor cells on changes to permeability across an endothelial monolayer using a trans-well permeability assay that measures solute (FITC-dextran) flux 
across endothelial monolayers. Permeability was monitored across a four-hour time course and CM from hypoxic tumor cells was used to induce permeability across the HMEC-1 monolayer. Effect of inhibin in the $\mathrm{CM}$ was evaluated either in the presence of anti-inhibina (PO23 and R1) or IgG control (Fig. 3Ci-ii). We find that both inhibina antibodies (R1 and P023) significantly decreased solute flux induced by hypoxic $\mathrm{CM}$ from two tumor cell lines, albeit with moderate differences in the kinetics and time to inhibition (Fig. 3Ci-ii). Specifically, significant inhibition of permeability was seen beginning at two hours for CM treated with P023 and three hours for R1. P023 was moderately more effective than R1 as it effectively reduced permeability within 1 hour (Fig. 3Ci-ii). Recombinant inhibin was also able to induce endothelial cell permeability to similar extents as LPS (Fig. 3D), an established permeability inducing factor ${ }^{43}$. Since perturbations to the endothelial barrier are critical to invasion and extravasation of cancer cells during metastasis ${ }^{53}$, we tested whether inhibin induced vascular permeability facilitates tumor cell extravasation. To test this, we used a trans-endothelial cell migration assay to mimic the process. HEY tumor cells infected with GFP adenovirus to distinguish them from migrated non-GFP endothelial cells were plated on top of a non-GFP endothelial cell monolayer that was then either pre-treated with $1 \mathrm{nM}$ inhibin A for 4 hours or left untreated. We find that HEY GFP tumor cells, were 2.9-times more invasive across the inhibin treated monolayer than untreated conditions (Fig. 3Eii-iii). All together, these data implicate inhibin as a robust contributor to hypoxia mediated angiogenesis, vascular permeability and thereby tumor cell extravasation across the vascular endothelium.

\section{Inhibin promotes vascular permeability through increased VE-cadherin trafficking.}

Endothelial permeability is regulated through changes in junctional proteins which are maintained through contacts with the actin cytoskeleton ${ }^{54}$. VE-cadherin is a critical junctional protein involved in regulating endothelial cell permeability ${ }^{54}$. To delineate the mechanism of inhibin's effects on vascular permeability, we first evaluated the effect of inhibin on endothelial cell junctions and the actin cytoskeleton through immunofluorescent staining of VE-cadherin and actin (Fig. 4A). Examination of the actin cytoskeleton revealed significant contractile actin staining, with a significant increase in stress fiber formation after 30 minutes of inhibin A treatment (two times increase, Fig. 4Ai-ii). VEGF A treatment was used as a comparison that also led to similar changes in actin stress fiber formation (Fig. 4A). VEcadherin localization also appeared to be reduced qualitatively at the cell-cell junctions after 30 minutes of inhibin treatment as compared to untreated cells, suggestive of perturbation of the endothelial cell barrier at the level of the cytoskeleton (Fig. 4A). Loss of VE-cadherin at the cell junctions was also observed in VEGF A treated cells (Fig. 4A). However, total VE-cadherin levels were unchanged in response to inhibin as evaluated over a time course of 60 minutes (Supp Fig. 4) indicating no change in the total pool of VE-cadherin in response to inhibin A. Actin contractility and stress fiber assembly is regulated through phosphorylation of myosin light chain (MLC) ${ }^{54}$. In accordance, we find that phosphorylation of MLC-2 (Ser19) increased within 5 minutes of inhibin A treatment and was sustained across a 60-minute time course (Fig. 4Bi-ii). Based on the qualitative changes in VE-cadherin in response to inhibin $\mathrm{A}$ treatment (Fig. 4A), we tested whether alterations in VE-cadherin at the cell-cell junctions were due to inhibin induced VE-cadherin internalization (Fig. 4C). To determine this, HMEC-1 membrane localized VE- 
cadherin was labeled at $4^{\circ} \mathrm{C}$ with an anti-VE-cadherin antibody recognizing the extra-cellular domain. HMEC-1 cells were washed with acid to remove membrane bound anti-VE-cadherin leaving only any internalized VE-cadherin that may have been labeled at $4^{\circ} \mathrm{C}$ prior to treatment with inhibin A or VEGF A (Fig. 4Ci). Stripping of cell surface VE-cadherin was verified by cell surface immunostaining of VEcadherin with little to no internalized VE-cadherin detected (Fig. 4Cii,iv). Cells were then either left untreated or treated for 30 minutes with inhibin $A$ at $37^{\circ} \mathrm{C}$ and VE-cadherin evaluated by immunofluorescence (Fig. 4Ciii). We find that inhibin A increased the internalized VE-cadherin pool compared to untreated cells 1.4-times (Fig. 4CV) and to similar extents as VEGF A (1.6-times, Fig. 4CV). These results indicate that inhibin induces rapid changes in the actin cytoskeleton and trafficking of VEcadherin from the cell junctions of endothelial cells.

\section{Inhibin's effects on vascular permeability are mediated by ALK1 and CD105/endoglin that form a stable complex at the cell surface in response to inhibin}

Previously, we demonstrated that inhibin's effects on angiogenesis and endothelial cell signaling were dependent on the TGF $\beta$ receptors ALK1 and endoglin ${ }^{19}$. To evaluate if ALK1 and endoglin are required for inhibin's influence on vascular permeability, we treated HMEC-1 cells with TRC105, a humanized endoglin monoclonal antibody ${ }^{55}$, or with ALK1-Fc, a human chimeric ALK1 protein ${ }^{56}$. At four hours, treatment with (i) TRC105 and (ii) ALK1-Fc decreased inhibin A induced permeability by 2.2 and 1.5-times, respectively (Fig. 5A, Supp Fig. 5 for full time course) indicating both ALK1 and endoglin are required for inhibin's effects on endothelial cell permeability.

We next evaluated if internalization of VE-cadherin by inhibin was dependent on endoglin using mouse embryonic endothelial cells (MEEC) that are either wild type (WT) or null for endoglin expression ${ }^{51}$ (Supp Fig. 6). Cell surface biotinylation of VE-cadherin was used to quantitatively assess VE-cadherin internalization. Towards this, cell surface proteins were labeled with Sulfo-NH-SS biotin and allowed to internalize for 30 minutes at $37^{\circ} \mathrm{C}$ in the presence or absence of inhibin followed by stripping of cell surface biotin, immunoprecipitation with neutravidin resin and immunoblotting to detect internalized biotin labeled VE-cadherin (Fig. 5Bi). Treatment with inhibin A increased internalized VE-cadherin 1.9times in MEEC WT compared to control (Fig. 5Bi), similar to extents seen by immunofluorescence in HMEC-1 cells (Fig. 4C). However, in the absence of endoglin in MEEC ENG-/- cells inhibin A did not change the internalized VE-cadherin pool (Fig. 5Bii). This data indicates that endoglin is essential for inhibins effects on VE-cadherin.

Based on the significant dependency of inhibin's effects on endothelial cell permeability and VE-cadherin internalization on endoglin and ALK1 respectively (Fig. 5A,B), we evaluated biophysically, in a sensitive and quantitative manner, the extent of the endoglin-ALK1 interaction in response to inhibin. We utilized a patch/FRAP (fluorescence recovery after photobleaching) methodology to measure interactions between endoglin and ALK1 at the surface of live cells. This method differentiates between stable and transient interactions as described in detail previously ${ }^{57}$. Herein, one receptor carrying an extracellular epitope tag is patched and immobilized through cross-linking with a double layer of IgGs. The effects of this 
immobilization on the lateral diffusion of a co-expressed, differently-tagged receptor labeled exclusively with Fab' fragments are then measured by FRAP (Methods). Stable complex formation between the two co-expressed receptors (complex lifetimes longer than the characteristic FRAP fluorescence recovery time) reduces the mobile fraction $\left(R_{f}\right)$ of the Fab'-labeled receptor, since bleached Fab'-labeled receptors associated with immobilized receptors do not appreciably dissociate from the immobile patches during the FRAP measurement. On the other hand, transient complexes (short complex lifetimes) would reduce the apparent lateral diffusion coefficient $(D)$, since each Fab'-labeled receptor molecule can undergo multiple association-dissociation cycles during the FRAP measurement ${ }^{57}$. For these studies, COS7 cells were transfected with myc-ALK1, HA-endoglin or co-transfected with both, and subjected to patch/FRAP experiments in the absence or presence of $4 \mathrm{nM}$ of inhibin A (Fig. 5C). Fig. 5Ci-iii depict representative FRAP curves showing the lateral diffusion of myc-ALK1 (Fig. 5Ci), IgG-crosslinked and immobilized HAendoglin (Fig. 5Cii), and myc-ALK1 co-transfected with HA-endoglin followed by IgG cross-linking of HAendoglin in the presence of inhibin (Fig. 5Ciii). Average values derived from multiple independent experiments are shown in $\left(R_{f}\right.$ in Fig. $5 \mathrm{Cv}, D$ values in Fig. $\left.5 \mathrm{Cv}\right)$. Singly expressed myc-ALK1 had lateral mobility resembling other TGF- $\beta$ superfamily receptors ${ }^{34}$, which was insensitive to inhibin treatment (Fig. $5 \mathrm{Ci}$ and iv). Immobilization of HA-endoglin (Fig. $5 \mathrm{Cii}$ and iv) reduced $R_{f}$ of myc-ALK 1 by about $45 \%$, and the presence of inhibin increased this reduction significantly (from $45-70 \%$ reduction) (Fig. 5 Ciii and iv). Under all these conditions, the lateral diffusion coefficient $(D)$ of myc-ALK1 was not significantly affected (Fig. $5 \mathrm{Cv}$ ), indicating that endoglin and ALK1 form stable complexes at the plasma membrane which are enhanced and stabilized by inhibin.

Previous studies indicate that inhibina may bind to $A L K 4^{58}$, an established Type I receptor for the Activin family of proteins ${ }^{8}$. We thus employed patch/FRAP to determine the interactions between endoglin and ALK4 and to examine whether inhibin A enhanced these interactions. To this end, we expressed HA-ALK4, myc-endoglin or both in COS7 cells, and subjected them to patch/FRAP studies on the lateral diffusion of HA-ALK4 without and with IgG cross-linking of myc-endoglin, and with or without inhibin A. In the absence of inhibin A, endoglin and ALK4 exhibited significant stable interactions, as demonstrated by the reduction in $R_{f}$ of HA-ALK4 upon immobilization of myc-endoglin ( $40 \%$ reduction in $R_{f}$ with no effect on the $D$ value) (Fig. 5Di-ii). However, in contrast to the observations with endoglin-ALK1 complexes, the interactions between endoglin and ALK4 were weakened in the presence of inhibin A (the reduction in $R_{f}$ decreased to 20\%) (Fig. 5Di). Taken together, these results indicate that inhibin shifts the balance of endoglin complexes from interactions with ALK4 to interactions with ALK1, both of which (endoglin and ALK1) are required for inhibin mediated vascular permeability.

\section{Inhibin promotes hypoxia induced tumor growthin vivothrough alterations in permeability and angiogenesis}

The significance of hypoxia in ovarian cancer is well documented and we previously demonstrated increased ascites accumulation in tumor bearing mice in the presence of inhibin ${ }^{19}$. To precisely define the contribution of inhibin to hypoxia induced tumor growth and angiogenesis, we first evaluated the effects 
of pre-exposure to hypoxia on tumor growth in a subcutaneous model in vivo, a model that allows for quantitative analysis of the vasculature in tumors ${ }^{59}$. HEY pLKO.1 control vector (shControl) cells were preexposed to hypoxia $\left(0.2 \% \mathrm{O}_{2}\right)$ for $24 \mathrm{hrs}$ or kept under normoxia followed by injection into the right flank of Ncr nude mice. Tumors were measured throughout and harvested after 30 days ( $n=10$ mice). HEY cells pre-exposed to hypoxia produced rapid growing tumors compared to those that originated from normoxia grown cells (Fig. 6A, purple versus black line). In parallel, we utilized two methods to perturb inhibin: 1) shRNA knockdown of INHA in HEY cells (Supp Fig. 7A,B) and 2) intraperitoneal administration of antiinhibina antibody (R1). R1 is a human antibody ${ }^{51}$ and consistent with this no overall toxicity was noted in pilot toxicity studies that utilized daily injections of R1 (Supp Fig. 7C). sh/NHA cells exposed to hypoxia maintained their knockdown to INHA at the end of the study (Supp Fig. 7B) and produced tumors with significantly slower growth rates than shControl hypoxia tumors (Fig. 6A, blue versus black lines). In complementary findings, hypoxia exposed tumor cells had significantly reduced tumor growth upon receiving treatment with the $\mathrm{R} 1$ antibody when compared to tumors in mice that received vehicle only (Fig. 6A, red versus blue line, $\mathrm{n}=6$ for $\mathrm{R} 1$ treated mice). The group receiving anti-inhibina (R1) grew at a similar rate as the sh INHA hypoxia tumors (Fig. 6A, red versus blue line). In mice with sh INHA tumors, treatment with R1 further reduced tumor growth albeit moderately compared to vehicle sh INHA (Fig. 6A, blue versus green line). These data indicate that perturbation of inhibin through shRNA targeting and antiinhibin antibody treatment reduces tumor growth. We hence sought to determine the effect of sh INHA on the angiogenic cytokine profile of the tumors using a proteome array of 55 different human angiogenesis targets. We find that the most up-regulated proteins in control tumors compared to sh/NHA tumors were a subset of pro-angiogenic cytokines IL8 (2.5-times) and EGF (2.1-times) (Fig. 6Bi) indicating a proangiogenic profile of the tumor cells in the presence of inhibin. In contrast, the sh/NHA hypoxia tumors showed increases in proteins including ADAMTS-1 (1.6-times) and Pentraxin-3 (1.3-times), indicating an anti- angiogenic profile in shINHA tumor cells as both have been demonstrated to be anti-angiogenic ${ }^{60,61}$. Activin $\mathrm{A}$ and endoglin were also found to be elevated in sh/NHA tumors (Fig. 6Bi). To complement the human tumor array, we analyzed changes in the mouse angiogenic proteome as well to delineate any host differences in response to shControl and sh INHA tumor cells. We find that host cells also upregulated significantly more pro-angiogenic proteins, including CXCL $16^{62}, \mathrm{PIGF}-2^{63}$, and NOV ${ }^{64}$ in shControl tumors compared to sh/NHA tumors ( Fig. 6Bii). Taken together, these data suggest that altering inhibin in the tumors results in a change in the balance of angiogenic factors leading to a significant reduction in pro-angiogenic factors and slower overall tumor growth.

To rule out whether the reduction in tumor growth in sh/NHA cells was due to slower proliferation of tumor cells, growth rate of HEY sh INHA and HEY shControl was evaluated in culture under hypoxia for 3 days. No significant change was observed (Supp Fig. 7D) suggesting that the major effect of inhibin on tumor growth are likely through effects on the tumor vasculature due to the effects of hypoxia regulated inhibin on angiogenesis and vascular permeability in vitro (Fig. 4,5). We thus determined the effect of inhibin on the tumor vasculature and associated permeability changes as a contributing factor to the altered tumor growth in sh INHA and antibody treated hypoxia tumors (Fig. 6A). To this end, HEY shControl or sh $/ N H A$ cells pre-exposed to hypoxia for $24 \mathrm{hrs}$ were injected subcutaneously into the right 
flank of Ncr nude mice ( $\mathrm{n}=4$ mice, Fig. 6B) and tumors in all groups were harvested upon reaching 700$850 \mathrm{~mm}^{3}$ (Fig. $6 \mathrm{Ci}$ ) to eliminate any tumor size effects on angiogenesis. These tumors (Fig. $6 \mathrm{Ci}$ ) were evaluated for changes in vascular permeability by visualization of a rhodamine-dextran dye that leaks from the blood vessels into the tumors when administered into mice prior to sacrifice. We find that rhodamine-dextran was present at 5.5-times higher levels in shControl tumors compared to sh INHA tumors indicating higher vascular permeability within the tumors in the presence of inhibin (Fig. 6Cii-iii). To further characterize the differences in the vasculature between shControl and sh INHA tumors, blood vessels were stained with CD-31 to evaluate vessel number and size (Fig. 6D). We find an increase in the total number of blood vessels in shControl tumors compared to sh/NHA tumors (Fig. 6Di,iii). Quantitation of the size of the vessels revealed significantly smaller vessels in shControl tumors as compared to the sh INHA tumors (Fig. 6Dii,iii). These data together demonstrate that reducing inhibin in the tumor decreases vascular leakiness, alters vessel size and numbers and promotes more normalized vasculature in the tumors.

\section{Discussion}

Hypoxia significantly impacts several aspects of tumor progression by regulating pathways that can be targeted for cancer management, particularly angiogenic mechanisms. We have for the first time identified inhibins', that are well established biomarkers for ovarian and other cancers and a member of the TGF $\beta$ superfamily, to be targets of the hypoxic response. We significantly extended our previous findings ${ }^{19}$ to demonstrate that hypoxia induced tumor growth, angiogenesis and vascular leakiness is accompanied with, and dependent on inhibin levels in cells and tumors, and relevant to the ovarian cancer patient population. In keeping with this, hypoxia induced tumor growth can be suppressed by treatment with a selective inhibin antibody that leads to a shift in the angiogenic balance in tumors. We also provide mechanistic evidence for the involvement of ALK1 and endoglin in inhibin's effects on permeability via increased VE-cadherin internalization. Due to the lack of systemic inhibin expression in post-menopausal women, establishing the therapeutic significance of targeting inhibin in this patient population may be particularly beneficial to evade systemic side effects seen with targeting other hypoxia associated angiogenic pathways.

Significant information exists on the cycling levels of inhibins' in premenopausal women, the decline of inhibin during peri-menopause, and as a marker whose decline defines the onset of menopause leading to complete absence of inhibin in normal post-menopausal women ${ }^{13}$. Contrastingly, several studies have reported elevated levels of Inhibin in a subset of cancers ${ }^{14,15,17,36}$. Our studies shed light on the potential mechanisms leading to elevated inhibin. We also find that total inhibin is elevated in the ascites fluid of patients with ovarian cancer, a hypoxic environment that aids in dissemination of shed ovarian cancer spheroids $^{22,43}$ (Fig. 1). Serum inhibin and CA125 levels are both markers for ovarian cancer ${ }^{17,18}$ and were also positively correlated with each other in these patient ascites fluid (Supp Fig. 8A). Menopause status was unknown in these patients however the median age of the cohort was 62 and only two patients were below 50 years of age (Supp Fig. 8B). INHA expression and hypoxia are also correlated through a hypoxia 
gene score (Fig. 1G). Supporting our hypothesis that inhibin is regulated by hypoxia, we also found that exposure of ovarian cancer cells to hypoxia increased INHA expression and inhibin secretion (Fig. 1). Surprisingly, we did not note consistent and statistically significant increases in the activin subunits, INHBA or INHBB which only appeared to be moderately elevated (Fig. 1) indicating that increased secretion levels were driven by inhibina. Previous reports indicate activin, specifically INHBA, increases in response to hypoxia in endothelial cells ${ }^{65}$. However, here the increase in INHA levels in endothelial cells in response to hypoxia was only moderate as compared to in tumor cells (Fig. S1) suggesting a potential competition in the tumor microenvironment between activin and inhibin. The ELISA used here (Methods) does not discriminate between various forms of inhibin, inhibin $A / B$ or free alpha subunit, hence it is not clear if inhibin A levels are different from inhibin $B$ in secretion. Likely, an increase in just the alpha subunit (INHA) is enough to shift the dimerization of the beta subunits (INHBA/ INHBB) from activin homodimers to inhibin heterodimers.

Mechanistically, we find through knockdown studies and ChIP studies that INHA expression is regulated through the HIF-1 transcription factor binding directly to the INHA promoter (Fig. 2). Our findings on a hypoxia response in a pathological condition as seen here, is consistent with a previous report demonstrating that FSH can drive INHA expression in granulosa cells dependent on HIF-1 in what appeared to be in an indirect manner ${ }^{66}$. Intriguingly, evidence for INHA regulation by hypoxia, specifically dependent on HIF isoforms, has been demonstrated in cytotrophoblasts ${ }^{67}$. Here we present detailed and direct evidence of regulation by HIF-1, with HIF1 interacting at INHA's promoter to drive expression under hypoxia (Fig. 2). cAMP and PKA can be activated in response to hypoxia as well. However, the PKA inhibitor, $\mathrm{H} 89$, was not able to reduce hypoxia induced INHA expression indicating that CAMP may not be involved in the hypoxia transcriptional regulation of INHA (Fig. S3). This does not preclude a role for cAMP-PKA in the regulation of INHA as it is well established that the CAMP-PKA signaling axis enhances tumorigenesis in ovarian cancer ${ }^{68}$. As the effect of forskolin was additive on INHA expression, cAMP and PKA could represent an alternative or additive mechanism of regulation of INHA in ovarian cancer.

In prostate and adrenocortical cancers reports of both increased and decreased inhibina levels have been reported $^{15,69,70}$. In adrenocortical tumors with lower INHA levels, methylation of the INHA promoter was reported to occur at the $\mathrm{CpG}$ island within the proximal HRE site that we identified, suggesting potential roles for epigenetic regulation of INHA as well ${ }^{70}$. HIF transcription factors have reduced binding to methylated hypoxia response elements ${ }^{71}$. To this end, it is possible that not all cell lines will increase inhibin expression in response to hypoxia. If this is the case, methylation of INHA's promoter may play a role making further understanding of the regulation of INHA expression, particularly in patients necessary in the future.

Previously we also demonstrated inhibin's effects broadly on angiogenesis ${ }^{19}$. Here, we sought to define more precisely the outcomes of inhibin's effects on angiogenesis, specifically in the context of hypoxia. Using recombinant inhibin and antibodies to the alpha subunit of inhibin, we find novel roles for inhibin as a permeability inducing factor with implications for tumor cell extravasation (Fig. 3). Inhibin induced 
permeability was dependent on ALK1 and endoglin (Fig. 5A). The VE-cadherin dependent mechanism of permeability observed by us (Fig. 4) is consistent with prior findings on the effects of other TGF $\beta$ family members' roles in promoting vascular permeability, specifically BMP6 ${ }^{30}$. BMP6 induced vascular permeability was mediated through the Type 1 receptor ALK2 ${ }^{30}$, whereas we expect the Type 1 receptor ALK1 to be more critical for inhibin induced vascular permeability. Interestingly, inhibin strongly increased the stable interaction between ALK1 and endoglin (Fig. 5C), in line with our observation that both endoglin and ALK1 are required for permeability, and endoglin being critical for VE-cadherin internalization (Fig. 5). These findings have broad implications for other TGF $\beta$ family members that may regulate permeability dependent on Type 1 receptors. The patch/FRAP studies (Fig. 5) support our current and previous findings ${ }^{19}$. Although there are some reports suggesting that inhibin can bind to ALK4 ${ }^{58}$, our findings show that inhibin does not enhance endoglin-ALK4 complex formation but rather weakens it (Fig. 5D). We have previously demonstrated that endothelial cells such as HMEC-1 express very little ALK4 compared to $A L K 1^{19}$, supporting the idea that inhibin acts in endothelial cells preferentially via ALK1 in line with a potential physiological relevance of inhibin-mediated increase in endoglin-ALK1 interactions. However, these findings in endothelial cells do not contradict the current understanding of inhibin's function in non-endothelial cells, which may express more ALK4 than ALK1. These findings also do not allow us to conclude whether the ALK1-endoglin complex, which is enhanced by the binding of inhibin, is signaling or kinase competent, as non-signaling receptor complexes may exist and impact signaling in an indirect manner. Such complexes were previously reported in the context of activin and ALK2 ${ }^{72,73}$ and need further examination for inhibins.

Targeting inhibin through shRNA knockdown and antibody treatment was found to be an effective antiangiogenic strategy leading to reduced vascular permeability increased blood vessel size but fewer number of vessels and a likely more normalized vasculature (Fig. 6D). Interestingly, in our analysis of the angiogenic proteome of HEY tumors, permeability promoting cytokines, EGF, IL-8, and DPP4 were significantly lower in sh/NHA tumors which were less permeable as compared to shControl tumors (Fig. 6B). Interestingly, the sh INHA tumor cells produced more activin and endoglin compared to shControl tumors (Fig. 6Bi). Increased activin fits the profile of the sh INHA tumors expressing more antiangiogenic proteins as activin has been shown to inhibit angiogenesis ${ }^{7}$ which could also be a result of decreased inhibina thus shifting the balance to increased dimerization of INHBA/B and thereby activin production. Similarly, increases in tumor cell endoglin levels in sh INHA tumors in vivo may reflect compensatory responses to changes in inhibin expression consistent with recent reports on endoglin expression changes in ovarian cancers ${ }^{74}$. Whether these changes impact metastasis and angiogenesis and are directly related to changes in inhibin levels in patients remains to be examined. Which of these altered proteins contributes the most to the either pro or anti-angiogeneic tumor microenvironment remains to be determined as we unravel new roles for inhibins herein.

In the mouse host cells where inhibin is likely to interact with endoglin from the endothelia to affect angiogenesis, endoglin levels were slightly higher in shControl receiving hosts that had more vessels 
compared to sh/NHA (Fig. 6Dii). These findings also suggest that blocking inhibin could shift the balance between pro and anti-angiogenic genes.

We also demonstrate for the first time that anti-inhibin in a therapeutic regimen can reduce tumor growth in vivo (Fig. 6A). The subcutaneous model utilized does not induce ascites formation, unlike the intraperitoneal model used previously, where mice with sh/NHA tumors produced less ascites than those with shControl tumors ${ }^{19}$. However, this model was chosen as it better allows for evaluation of the vasculature in vivo. Our findings that inhibin is elevated in patient ascites (Fig. 1E) supports the idea that inhibin may promote ascites formation, likely through increased vascular permeability. The effectiveness of anti-angiogenic therapies is attributed to increased vascular normalization resulting in reduced intratumoral hypoxia, perfused and functional vessels that improve delivery of other chemotherapeutics and enhanced immune response ${ }^{75}$. Resistance to current anti-angiogenic therapies is also common and inhibin A levels have been reported to be increased in patients non-responsive to anti-angiogenic therapy ${ }^{76}$ (combination of TRC105 and Bevacizumab) indicating inhibin as a potential alternative mechanism of angiogenesis in tumors resistant to other anti-angiogenic therapies. Further studies exploring the impact of anti-inhibin therapy on the effectiveness of chemotherapeutics and anti-tumor immune response as well is most certainly warranted.

\section{Conclusion}

In conclusion, our study shows that targeting inhibin is an effective anti-angiogenic strategy. We demonstrate for the first time a contextual mechanism for the regulation of inhibin directly driven by hypoxia and HIF-1 and fully define inhibin's contributions to hypoxia induced angiogenesis. Based on our findings and the previously known physiological functions of inhibin, we speculate that targeting inhibin may have potential improved therapeutic value in post-menopausal cancers including a significant percentage of ovarian cancers.

\section{Abbreviations}

ALK1: activin receptor-like kinase 1

ALK2: activin receptor like-kinase 2

ALK4: activin receptor-like kinase 4

BMP6: bone-morphogenic protein 6

BMP9: bone-morphogenic protein 9

cAMP: cyclic adenosine monophosphate

ChIP: chromatin immunoprecipitation 
CM: conditioned media

$\mathrm{CoCl}_{2}$ : cobalt chloride

CREB: CAMP response element binding protein

DPP4: dipeptidyl peptidase 4

EGF: epidermal growth factor

ELISA: enzyme linked immunosorbent assay

ENG/CD105: endoglin

FBS: fetal bovine serum

FITC: fluorescein isothiocyanate

FRAP: fluorescent recovery after photobleaching

FSH: follicle stimulating hormone

Fsk: forskolin

GFP: green fluorescent protein

HAS: hypoxia ancillary sequence

HIF: hypoxia inducible factor

HMEC-1: human microvascular endothelial cells

HRE: hypoxia response element

IL-8: interleukin 8

LH: luteinizing hormone

LPS: lipopolysaccharide

MEEC: mouse embryonic endothelial cells

MLC: myosin light chain

mRNA: messenger RNA

NBF: neutral buffered formalin 
PKA: protein kinase $A$

qRT-PCR: quantitative real-time polymerase chain reaction

TGFb: transforming growth factor beta

TRC105: Tracon 105

VEGF: vascular endothelial growth factor

\section{Declarations}

\section{Data Availability}

All data generated or analyzed during this study are included in this published article and its supplementary information files.

\section{Acknowledgements}

We would like to acknowledge Mehri Monavarian, Victoria Alers and Hailey Young for technical assistance. We also thank the UAB High Resolution Imaging facility (HRIF), the Functional Genomics Core at University of South Carolina for lentiviral preparations and the UAB Heflin Center for genomic science core laboratories at UAB for cell line authentication services.

\section{Funding}

Funding for this work was provided by NIH R01CA219495 to Mythreye Karthikeyan (KM).

The funders had no role in study design, data collection and analysis, decision to publish, or preparation of the manuscript.

\section{Competing Interest Statement}

The authors declare no potential conflicts of interest.

\section{Consent for Publication}

Not applicable.

\section{Ethics Approval and Consent to Participate}

Specimens from patients diagnosed with primary ovarian cancer were collected and banked after informed consent at Duke University Medical Center, with approval for the study from Duke University's institutional research ethics board. All animal studies and mouse procedures were conducted in accordance with ethical procedures after approval by UAB's IACUC prior to study commencement. 
Authors Information

Affiliation

Department of Pathology, University of Alabama at Birmingham, Birmingham, AL, USA

Ben Horst, Eduardo Listik, Alex Seok Choi, and Karthikeyan Mythreye

Department of Chemistry and Biochemistry, University of South Carolina, Columbia, SC 29208, USA

Ben Horst, Shrikant Pradhan and Michael Southard, Karthikeyan Mythreye

School of Neurobiology, Biochemistry and Biophysics, George S. Wise Faculty of Life Sciences, Tel Aviv University, Tel Aviv 6997801, Israel

Roohi Chaudhary and Yoav Henis

Department of Medicine and Duke Cancer Institute, Duke University Medical Center, Durham NC

Yingmiao Liu and Andrew B Nixon

Department of Obstetrics and Gynecology, Duke University Medical Center, Durham NC

Duke University, Durham NC

Regina Whitaker and Andrew Berchuck

Department of Medicine, Division of Hematology Oncology, University of Pittsburgh School of Medicine Pittsburgh PA 15213

Nadine Hempel

Division of Pharmacology, Chemistry and Biochemistry, College of Medicine, University of Arizona, Tucson, AZ, 85721, USA.

Nam Lee

Contributions

$\mathrm{BH}, \mathrm{SP}, \mathrm{RH}, \mathrm{EL}, \mathrm{ASC}, \mathrm{MS}$ and $\mathrm{YL}$ conducted experiments.

$\mathrm{BH}$ and $\mathrm{KM}$ conceptualized, designed, analyzed data, wrote and edited the manuscript.

KM provided funding for the studies

YH designed, analyzed and wrote the manuscript. 
$\mathrm{ABN}, \mathrm{NH}$ and $\mathrm{NYL}$ edited the manuscript and analyzed data.

RW and $A B$ provided clinical samples.

\section{Corresponding Author}

Correspondence to Karthikeyan Mythreye

\section{References}

1. Viallard, C. \& Larrivee, B. Tumor angiogenesis and vascular normalization: alternative therapeutic targets. Angiogenesis 20, 409-426, doi:10.1007/s10456-017-9562-9 (2017).

2. Adam, R. A. \& Adam, Y. G. Malignant ascites: past, present, and future. J Am Coll Surg 198, 9991011, doi:10.1016/j.jamcollsurg.2004.01.035 (2004).

3. Monk, B. J., Minion, L. E. \& Coleman, R. L. Anti-angiogenic agents in ovarian cancer: past, present, and future. Ann Oncol 27 Suppl 1, i33-i39, doi:10.1093/annonc/mdw093 (2016).

4. Impact of selective anti-BMP9 treatment on tumor cells and tumor angiogenesis. Mol Oncol 10, 1603-1620, doi:10.1016/j.molonc.2016.10.002 (2016).

5. Goumans, M. J., Liu, Z. \& ten Dijke, P. TGF-beta signaling in vascular biology and dysfunction. Cell Res 19, 116-127, doi:10.1038/cr.2008.326 (2009).

6. Maeshima, K., Maeshima, A., Hayashi, Y., Kishi, S. \& Kojima, I. Crucial role of activin a in tubulogenesis of endothelial cells induced by vascular endothelial growth factor. Endocrinology 145, 3739-3745, doi:10.1210/en.2004-0213 (2004).

7. Panopoulou, E. et al. Activin A suppresses neuroblastoma xenograft tumor growth via antimitotic and antiangiogenic mechanisms. Cancer Res 65, 1877-1886, doi:10.1158/0008-5472.CAN-04-2828 (2005).

8. Makanji, Y. et al. Inhibin at 90: from discovery to clinical application, a historical review. Endocr Rev 35, 747-794, doi:10.1210/er.2014-1003 (2014).

9. Meunier, H., Rivier, C., Evans, R. M. \& Vale, W. Gonadal and extragonadal expression of inhibin alpha, beta A, and beta B subunits in various tissues predicts diverse functions. Proc Natl Acad Sci U S A 85, 247-251, doi:10.1073/pnas.85.1.247 (1988).

10. Woodruff, T. K. \& Mayo, K. E. Regulation of inhibin synthesis in the rat ovary. Annu Rev Physio/ 52, 807-821, doi:10.1146/annurev.ph.52.030190.004111 (1990).

11. Tsonis, C. G., Hillier, S. G. \& Baird, D. T. Production of inhibin bioactivity by human granulosa-lutein cells: stimulation by LH and testosterone in vitro. J Endocrino/ 112, R11-14, doi:10.1677/joe.0.112r011 (1987).

12. Walton, K. L., Makanji, Y., Robertson, D. M. \& Harrison, C. A. The synthesis and secretion of inhibins. Vitam Horm 85, 149-184, doi:10.1016/B978-0-12-385961-7.00008-1 (2011). 
13. Overlie, I. et al. Inhibin A and B as markers of menopause: a five-year prospective longitudinal study of hormonal changes during the menopausal transition. Acta Obstet Gynecol Scand 84, 281-285, doi:10.1111/j.0001-6349.2005.00490.x (2005).

14. Shanbhag, S. A., Sheth, A. R., Nanivadekar, S. A. \& Sheth, N. A. Immunoreactive inhibin-like material in serum and gastric juice of patients with benign and malignant diseases of the stomach. $\mathrm{Br} J$ Cancer 51, 877-882, doi:10.1038/bjc.1985.133 (1985).

15. Balanathan, P. et al. Elevated level of inhibin-alpha subunit is pro-tumourigenic and pro-metastatic and associated with extracapsular spread in advanced prostate cancer. Br J Cancer 100, 1784-1793, doi:10.1038/sj.bjc.6605089 (2009).

16. McCluggage, W. G., Maxwell, P., Patterson, A. \& Sloan, J. M. Immunohistochemical staining of hepatocellular carcinoma with monoclonal antibody against inhibin. Histopathology 30, 518-522 (1997).

17. Walentowicz, P. et al. Serum inhibin A and inhibin B levels in epithelial ovarian cancer patients. PLoS One 9, e90575, doi:10.1371/journal.pone.0090575 (2014).

18. Robertson, D. M., Pruysers, E. \& Jobling, T. Inhibin as a diagnostic marker for ovarian cancer. Cancer Lett 249, 14-17, doi:10.1016/j.canlet.2006.12.017 (2007).

19. Singh, P. et al. Inhibin Is a Novel Paracrine Factor for Tumor Angiogenesis and Metastasis. Cancer Res 78, 2978-2989, doi:10.1158/0008-5472.CAN-17-2316 (2018).

20. Listik, E. et al. A bioinformatic analysis of the inhibin-betaglycan-endoglin/CD105 network reveals prognostic value in multiple solid tumors. PLoS One 16, e0249558, doi:10.1371/journal.pone.0249558 (2021).

21. Rankin, E. B. \& Giaccia, A. J. Hypoxic control of metastasis. Science 352, 175-180, doi:10.1126/science.aaf4405 (2016).

22. Ahmed, N. \& Stenvers, K. L. Getting to know ovarian cancer ascites: opportunities for targeted therapy-based translational research. Front Oncol 3, 256, doi:10.3389/fonc.2013.00256 (2013).

23. Pece-Barbara, N. et al. Endoglin null endothelial cells proliferate faster and are more responsive to transforming growth factor beta 1 with higher affinity receptors and an activated Alk1 pathway. $\mathrm{J}$ Biol Chem 280, 27800-27808, doi:10.1074/jbc.M503471200 (2005).

24. Huang, Z. et al. Targeting Dormant Ovarian Cancer Cells In Vitro and in an In Vivo Mouse Model of Platinum Resistance. Mol Cancer Ther 20, 85-95, doi:10.1158/1535-7163.MCT-20-0119 (2021).

25. Nakayama, J., Raines, T. A., Lynch, K. R. \& Slack-Davis, J. K. Decreased peritoneal ovarian cancer growth in mice lacking expression of lipid phosphate phosphohydrolase 1. PLoS One 10, e0120071, doi:10.1371/journal.pone.0120071 (2015).

26. Yan, Q., Bartz, S., Mao, M., Li, L. \& Kaelin, W. G., Jr. The hypoxia-inducible factor 2alpha N-terminal and $\mathrm{C}$-terminal transactivation domains cooperate to promote renal tumorigenesis in vivo. $\mathrm{Mol} \mathrm{Cell}$ Biol 27, 2092-2102, doi:10.1128/MCB.01514-06 (2007).

27. Martins-Green, M., Petreaca, M. \& Yao, M. An assay system for in vitro detection of permeability in human "endothelium". Methods Enzymol 443, 137-153, doi:10.1016/S0076-6879(08)02008-9 
(2008).

28. Boudaoud, A. et al. FibrilTool, an ImageJ plug-in to quantify fibrillar structures in raw microscopy images. Nat Protoc 9, 457-463, doi:10.1038/nprot.2014.024 (2014).

29. Allalou, A. \& Wahlby, C. BlobFinder, a tool for fluorescence microscopy image cytometry. Comput Methods Programs Biomed 94, 58-65, doi:10.1016/j.cmpb.2008.08.006 (2009).

30. Benn, A., Bredow, C., Casanova, I., Vukičević, S. \& Knaus, P. VE-cadherin facilitates BMP-induced endothelial cell permeability and signaling. J Cell Sci 129, 206-218, doi:10.1242/jcs.179960 (2016).

31. Lee, N. Y., Kirkbride, K. C., Sheu, R. D. \& Blobe, G. C. The transforming growth factor-beta type III receptor mediates distinct subcellular trafficking and downstream signaling of activin-like kinase (ALK)3 and ALK6 receptors. Mol Biol Cel/ 20, 4362-4370, doi:10.1091/mbc.E09-07-0539 (2009).

32. Henis, Y. I., Moustakas, A., Lin, H. Y. \& Lodish, H. F. The types II and III transforming growth factor-beta receptors form homo-oligomers. J Cell Bio/ 126, 139-154, doi:10.1083/jcb.126.1.139 (1994).

33. Gilboa, L., Wells, R. G., Lodish, H. F. \& Henis, Y. I. Oligomeric structure of type I and type II transforming growth factor beta receptors: homodimers form in the ER and persist at the plasma membrane. J Cell Biol 140, 767-777, doi:10.1083/jcb.140.4.767 (1998).

34. Rechtman, M. M., Nakaryakov, A., Shapira, K. E., Ehrlich, M. \& Henis, Y. I. Different domains regulate homomeric and heteromeric complex formation among type I and type II transforming growth factorbeta receptors. J Biol Chem 284, 7843-7852, doi:10.1074/jbc.M809215200 (2009).

35. Cerami, E. et al. The cBio cancer genomics portal: an open platform for exploring multidimensional cancer genomics data. Cancer Discov 2, 401-404, doi:10.1158/2159-8290.CD-12-0095 (2012).

36. Arola, J. et al. Expression of inhibin alpha in adrenocortical tumours reflects the hormonal status of the neoplasm. J Endocrino/ 165, 223-229, doi:10.1677/joe.0.1650223 (2000).

37. Ziyad, S. \& Iruela-Arispe, M. L. Molecular mechanisms of tumor angiogenesis. Genes Cancer 2, 1085-1096, doi:10.1177/1947601911432334 (2011).

38. Bu, S. et al. Epithelial ovarian cancer stem-like cells are resistant to the cellular lysis of cytokineinduced killer cells via HIF1A-mediated downregulation of ICAM-1. Int J Onco/ 55, 179-190, doi:10.3892/ijo.2019.4794 (2019).

39. Kawata, M., Sekiya, S., Kera, K., Kimura, H. \& Takamizawa, H. Neural rosette formation within in vitro spheroids of a clonal human teratocarcinoma cell line, PA-1/NR: role of extracellular matrix components in the morphogenesis. Cancer Res 51, 2655-2669 (1991).

40. Masiello, T. et al. A Dynamic Culture Method to Produce Ovarian Cancer Spheroids under Physiologically-Relevant Shear Stress. Cells 7, doi:10.3390/cells7120277 (2018).

41. Groome, N. P. et al. Detection of dimeric inhibin throughout the human menstrual cycle by two-site enzyme immunoassay. Clin Endocrinol (Oxf) 40, 717-723, doi:10.1111/j.1365-2265.1994.tb02504.x (1994).

42. Cancer Stat Facts: Ovarian Cancer, <https://seer.cancer.gov/statfacts/html/ovary.html> ( 
43. Kim, K. S. et al. Hypoxia enhances lysophosphatidic acid responsiveness in ovarian cancer cells and lysophosphatidic acid induces ovarian tumor metastasis in vivo. Cancer Res 66, 7983-7990, doi:10.1158/0008-5472.CAN-05-4381 (2006).

44. Gao, J. et al. Integrative analysis of complex cancer genomics and clinical profiles using the cBioPortal. Sci Signa/ 6, pl1, doi:10.1126/scisignal.2004088 (2013).

45. Buffa, F. M., Harris, A. L., West, C. M. \& Miller, C. J. Large meta-analysis of multiple cancers reveals a common, compact and highly prognostic hypoxia metagene. Br J Cancer 102, 428-435, doi:10.1038/sj.bjc.6605450 (2010).

46. Winter, S. C. et al. Relation of a hypoxia metagene derived from head and neck cancer to prognosis of multiple cancers. Cancer Res 67, 3441-3449, doi:10.1158/0008-5472.CAN-06-3322 (2007).

47. Yuan, Y., Hilliard, G., Ferguson, T. \& Millhorn, D. E. Cobalt inhibits the interaction between hypoxiainducible factor-alpha and von Hippel-Lindau protein by direct binding to hypoxia-inducible factoralpha. J Biol Chem 278, 15911-15916, doi:10.1074/jbc.M300463200 (2003).

48. Dengler, V. L., Galbraith, M. \& Espinosa, J. M. Transcriptional regulation by hypoxia inducible factors. Crit Rev Biochem Mol Biol 49, 1-15, doi:10.3109/10409238.2013.838205 (2014).

49. Simko, V. et al. Hypoxia induces cancer-associated CAMP/PKA signalling through HIF-mediated transcriptional control of adenylyl cyclases VI and VII. Sci Rep 7, 10121, doi:10.1038/s41598-01709549-8 (2017).

50. Depoix, C. L., Debieve, F. \& Hubinont, C. Inhibin alpha gene expression in human trophoblasts is regulated by interactions between TFAP2 and cAMP signaling pathways. Mol Reprod Dev 81, 10091018, doi:10.1002/mrd.22421 (2014).

51. Robertson, D. M. et al. Development of an inhibin alpha subunit ELISA with broad specificity. Mol Cell Endocrinol 180, 79-86 (2001).

52. Baratchi, S. et al. Molecular Sensors of Blood Flow in Endothelial Cells. Trends Mol Med 23, 850868, doi:10.1016/j.molmed.2017.07.007 (2017).

53. Shenoy, A. K. \& Lu, J. Cancer cells remodel themselves and vasculature to overcome the endothelial barrier. Cancer Lett 380, 534-544, doi:10.1016/j.canlet.2014.10.031 (2016).

54. Dejana, E. Endothelial cell-cell junctions: happy together. Nat Rev Mol Cell Bio/ 5, 261-270, doi:10.1038/nrm1357 (2004).

55. Rosen, L. S. et al. A phase I first-in-human study of TRC105 (Anti-Endoglin Antibody) in patients with advanced cancer. Clin Cancer Res 18, 4820-4829, doi:10.1158/1078-0432.CCR-12-0098 (2012).

56. Mitchell, D. et al. ALK1-Fc inhibits multiple mediators of angiogenesis and suppresses tumor growth. Mol Cancer Ther 9, 379-388, doi:10.1158/1535-7163.MCT-09-0650 (2010).

57. Pomeraniec, L., Hector-Greene, M., Ehrlich, M., Blobe, G. C. \& Henis, Y. I. Regulation of TGF-beta receptor hetero-oligomerization and signaling by endoglin. Mol Biol Cel/ 26, 3117-3127, doi:10.1091/mbc.E15-02-0069 (2015). 
58. Zhu, J. et al. Inhibin a-subunit $\mathrm{N}$ terminus interacts with activin type IB receptor to disrupt activin signaling. J Biol Chem 287, 8060-8070, doi:10.1074/jbc.M111.293381 (2012).

59. Forster, J. C., Harriss-Phillips, W. M., Douglass, M. J. \& Bezak, E. A review of the development of tumor vasculature and its effects on the tumor microenvironment. Hypoxia (AuckI) 5, 21-32, doi:10.2147/HP.S133231 (2017).

60. Lee, N. V. et al. ADAMTS1 mediates the release of antiangiogenic polypeptides from TSP1 and 2. EMBO J 25, 5270-5283, doi:10.1038/sj.emboj.7601400 (2006).

61. Presta, M., Foglio, E., Churruca Schuind, A. \& Ronca, R. Long Pentraxin-3 Modulates the Angiogenic Activity of Fibroblast Growth Factor-2. Front Immunol 9, 2327, doi:10.3389/fimmu.2018.02327 (2018).

62. Korbecki, J. et al. The Role of CXCL16 in the Pathogenesis of Cancer and Other Diseases. Int J Mol Sci 22, doi:10.3390/ijms22073490 (2021).

63. De Falco, S. The discovery of placenta growth factor and its biological activity. Exp Mol Med 44, 1-9, doi:10.3858/emm.2012.44.1.025 (2012).

64. Lin, C. G. et al. CCN3 (NOV) is a novel angiogenic regulator of the CCN protein family. J Biol Chem 278, 24200-24208, doi:10.1074/jbc.M302028200 (2003).

65. Merfeld-Clauss, S., Lu, H., Wu, X., March, K. L. \& Traktuev, D. O. Hypoxia-induced activin A diminishes endothelial cell vasculogenic activity. J Cell Mol Med 22, 173-184, doi:10.1111/jcmm.13306 (2018).

66. Alam, H. et al. Follicle-stimulating hormone activation of hypoxia-inducible factor-1 by the phosphatidylinositol 3-kinase/AKT/Ras homolog enriched in brain (Rheb)/mammalian target of rapamycin (mTOR) pathway is necessary for induction of select protein markers of follicular differentiation. J Biol Chem 279, 19431-19440, doi:10.1074/jbc.M401235200 (2004).

67. Depoix, C. L., de Selliers, I., Hubinont, C. \& Debieve, F. HIF1A and EPAS1 potentiate hypoxia-induced upregulation of inhibin alpha chain expression in human term cytotrophoblasts in vitro. Mol Hum Reprod 23, 199-209, doi:10.1093/molehr/gax002 (2017).

68. Zhang, H., Kong, Q., Wang, J., Jiang, Y. \& Hua, H. Complex roles of cAMP-PKA-CREB signaling in cancer. Exp Hematol Oncol 9, 32, doi:10.1186/s40164-020-00191-1 (2020).

69. Balanathan, P. et al. Epigenetic regulation of inhibin alpha-subunit gene in prostate cancer cell lines. J Mol Endocrinol 32, 55-67 (2004).

70. Hofland, J. et al. Inhibin alpha-subunit (INHA) expression in adrenocortical cancer is linked to genetic and epigenetic INHA promoter variation. PLoS One 9, e104944, doi:10.1371/journal.pone.0104944 (2014).

71. D'Anna, F. et al. DNA methylation repels binding of hypoxia-inducible transcription factors to maintain tumor immunotolerance. Genome Biol 21, 182, doi:10.1186/s13059-020-02087-z (2020).

72. Aykul, S. et al. Activin A forms a non-signaling complex with ACVR1 and type II Activin/BMP receptors via its finger 2 tip loop. Elife 9, doi:10.7554/eLife.54582 (2020). 
73. Olsen, O. E. et al. Activin A inhibits BMP-signaling by binding ACVR2A and ACVR2B. Cell Commun Signal 13, 27, doi:10.1186/s12964-015-0104-z (2015).

74. Bai, S. et al. CD105 Is Expressed in Ovarian Cancer Precursor Lesions and Is Required for Metastasis to the Ovary. Cancers (Basel) 11, doi:10.3390/cancers11111710 (2019).

75. Jain, R. K. Antiangiogenesis strategies revisited: from starving tumors to alleviating hypoxia. Cancer Cell 26, 605-622, doi:10.1016/j.ccell.2014.10.006 (2014).

76. Liu, Y. et al. Modulation of Circulating Protein Biomarkers in Cancer Patients Receiving Bevacizumab and the Anti-Endoglin Antibody, TRC105. Mol Cancer Ther 17, 2248-2256, doi:10.1158/15357163.MCT-17-0916 (2018).

\section{Figures}



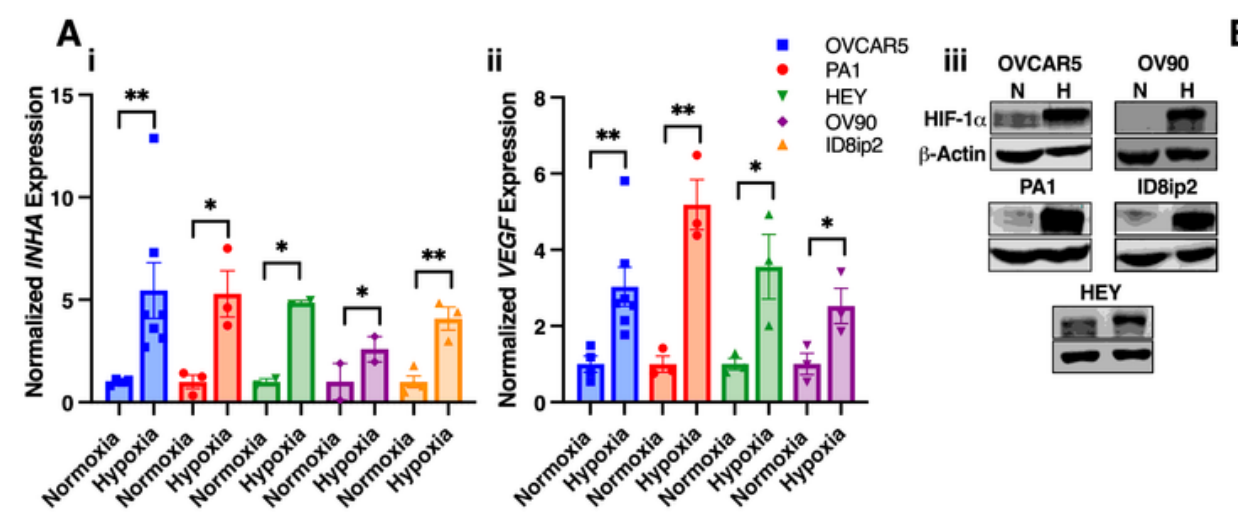

B
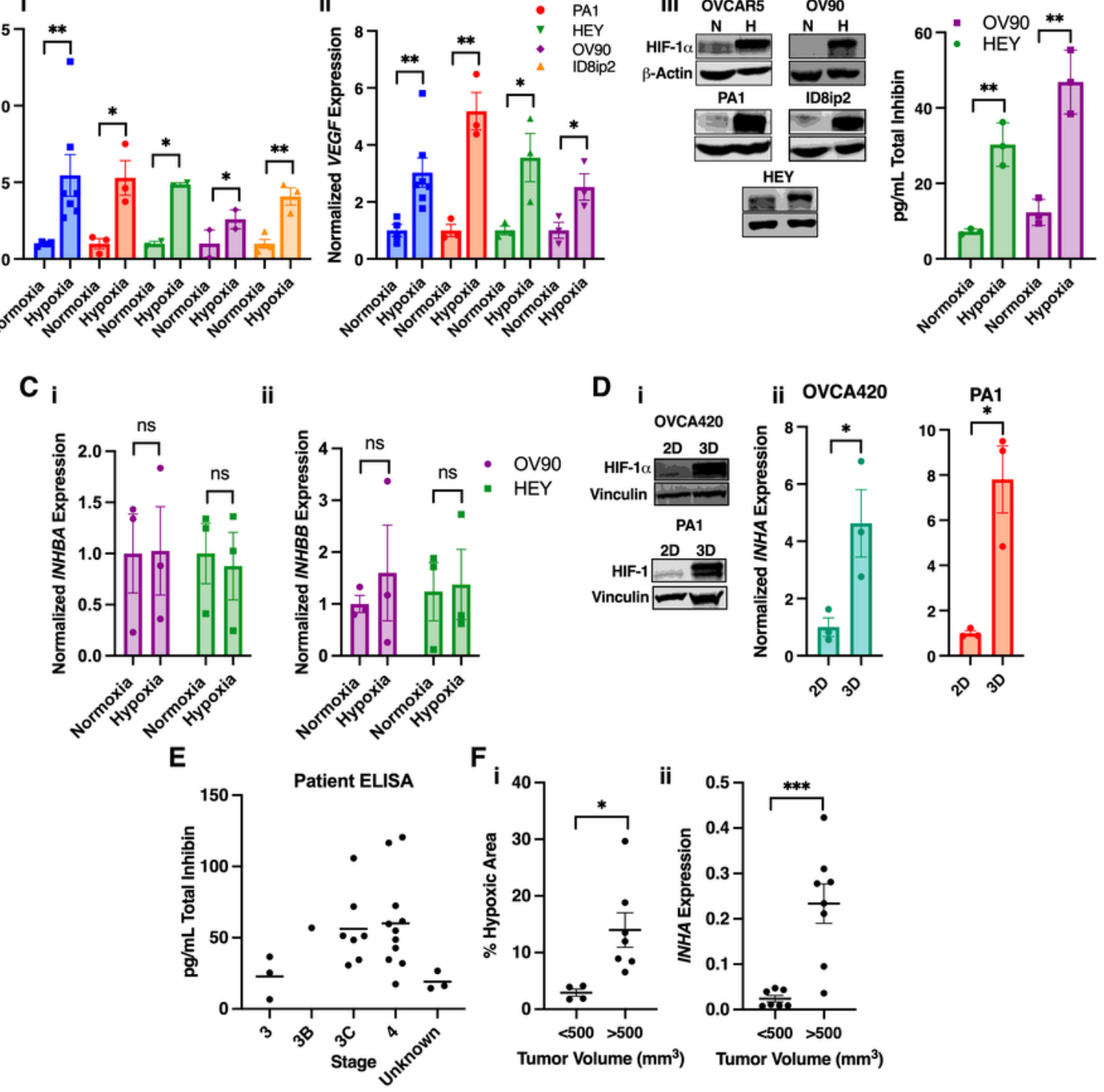

G i

ii
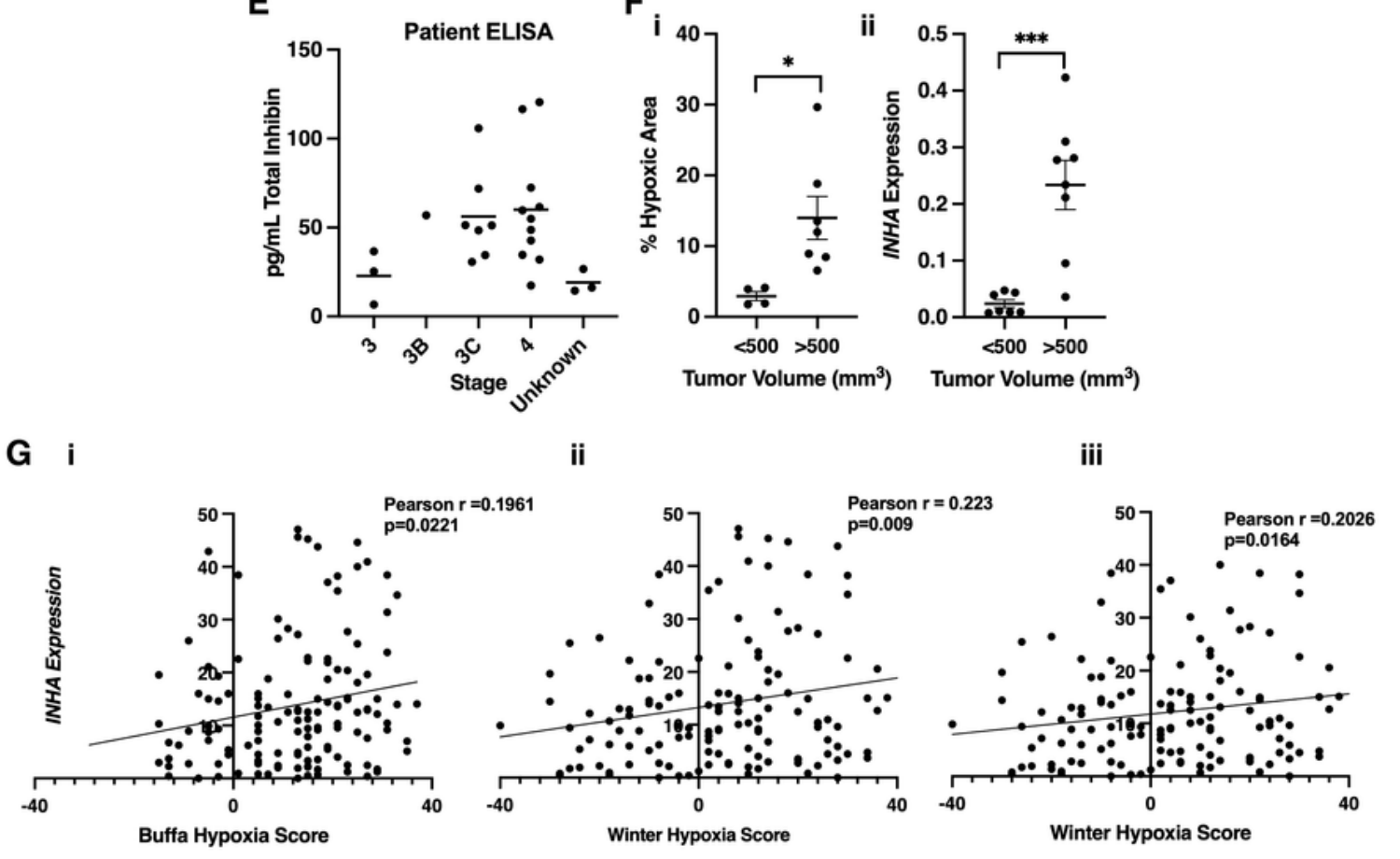

\section{Figure 1}

INHA and total inhibin protein are increased in response to hypoxia in ovarian cancer cells, spheroids, patient ascites and xenograft tumors and corelate with hypoxia signatures in patients A) qRT-PCR analysis of (i) INHA and (ii) VEGF mRNA expression normalized to corresponding normoxia in indicated cells grown under hypoxia (0.2\%) or normoxia (17-21\%) for 24hrs except for OVCAR5 and ID8ip2 (12hrs). Mean SEM, $n$ of independent trials for PA1 $=3$, OVCAR-5 $n=7, \operatorname{HEY} n=3$, OV90 $n=3$, ID8ip2 $n=4 . *$, $p<.05$; **, 
p<.01, unpaired t-test. (iii) Western blot of HIF-1 stabilization in indicated cell lines. B) Total inhibin ELISA (inhibin A/B, inhibin) of conditioned media (Methods) collected from OV90 and HEY cells grown in normoxia or after $24 \mathrm{hr}$ exposure to hypoxia $(0.2 \% 02)$. Mean SEM, $(n=3) .{ }^{*}, \mathrm{p}<.01$, unpaired t-test. C) qRTPCR of INHBA and INHBB mRNA expression in (i) OV90 and (ii) HEY after 24hrs of exposure to hypoxia $(0.2 \%$ 02) normalized to corresponding normoxia. Mean SEM, $n=3$. n.s., not significant, unpaired t-test. D) (i) HIF-1 protein expression by western blotting, vinculin is loading control, and (ii) qRT-PCR of INHA mRNA expression in OVCA420 and PA1 after 48hrs (OVCA420) or 72hrs (PA1) of growth under anchorage independence (3D) as compared to 2D. Mean SEM, $n=3 . * *, p<.01$; ${ }^{* \star *}, p<.001$, unpaired t-test. E) Total inhibin ELISA of ascites fluid from 27 ovarian cancer patients sorted by stage. F) (i) Average hypoxic area of HEY xenograft tumors calculated as a percent of hypoxic area normalized to total tumor volume. Mean SEM, $\mathrm{n}=4$ for $<500 \mathrm{~mm} 3$ and $\mathrm{n}=7$ for $>500 \mathrm{~mm} 3$. *, $\mathrm{p}<.05$, unpaired t-test. (ii) qRT-PCR of INHA expression in indicated tumor sizes of HEY cells implanted subcutaneously. Mean SEM, $n=8 . * \star \star, p<.001$, unpaired $t-$ test. (F) Correlation analysis between INHA expression and either (i) Buffa or (ii) Winter hypoxia scores from TCGA OVCA (i-ii) or breast (iii) cancer patient data sets from cBioportal measured by RNA-Seq. Correlation analysis was performed by Pearson correlation. 
A

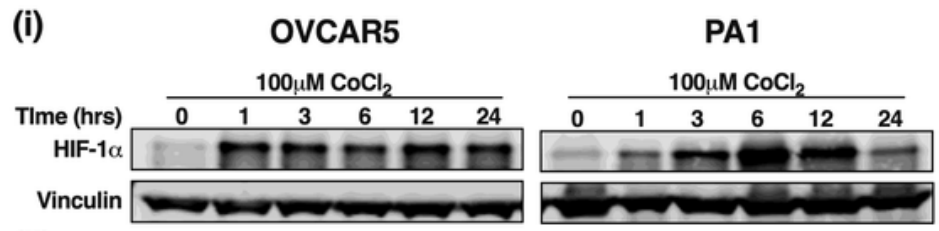

(ii)
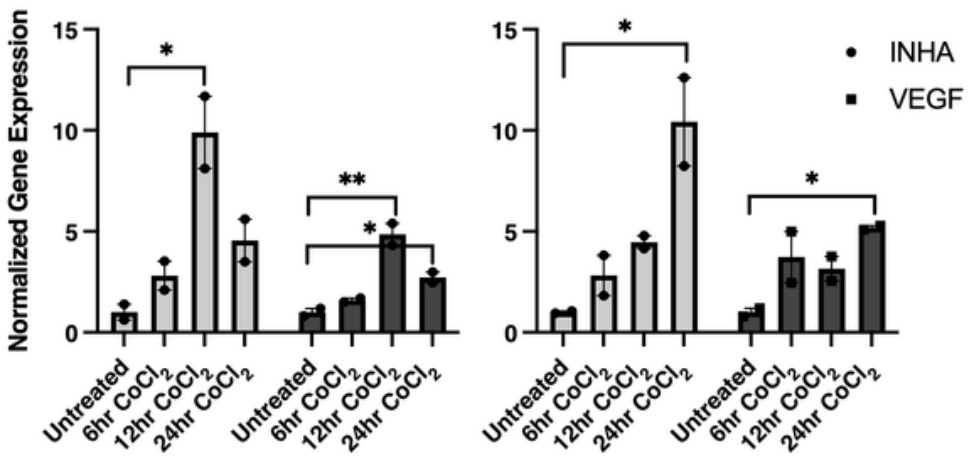

B

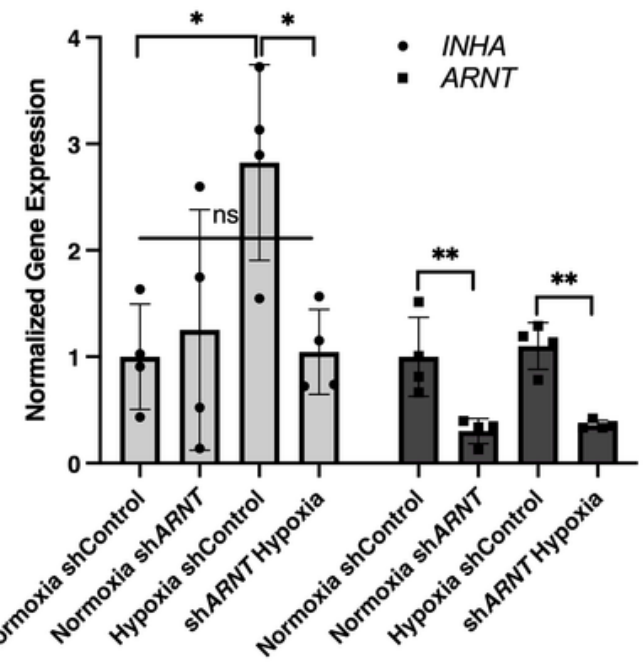

C (i)

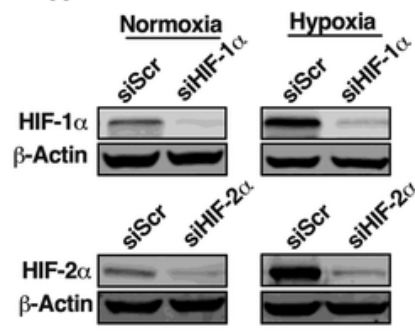

$D_{(i)}$

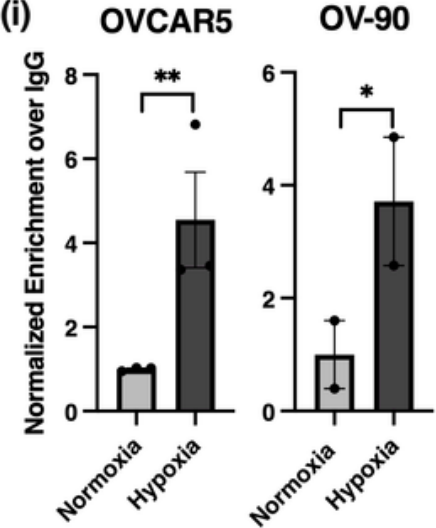

(ii)

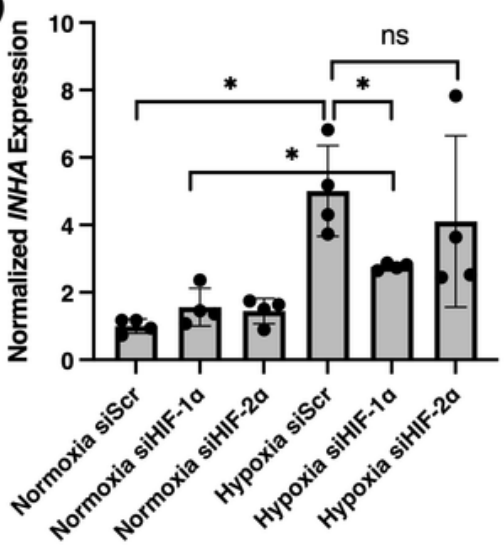

E (i)

(ii)

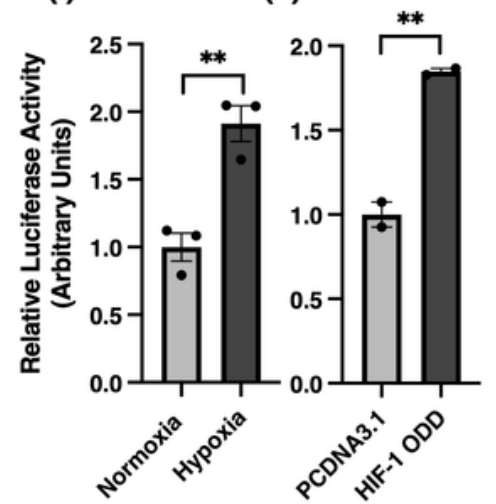

Figure 2

INHA expression is regulated by HIF-1. A) (i) Western blot of HIF-1 at indicated time points after treatment with $100 \mathrm{M} \mathrm{CoCl2.} \mathrm{(ii)} \mathrm{qRT-PCR} \mathrm{analysis} \mathrm{of} \mathrm{INHA} \mathrm{and} \mathrm{VEGF} \mathrm{mRNA} \mathrm{in} \mathrm{OVCAR5} \mathrm{and} \mathrm{PA1} \mathrm{cells} \mathrm{after}$ indicated time of treatment with $100 \mathrm{M}$ of $\mathrm{CoCl} 2$ normalized to untreated. Mean SEM, $(n=2)$. *, $p<.05$; **, p<.01, One-way ANOVA followed by Tukey's multiple comparison. B) qRT-PCR analysis of INHA and ARNT mRNA in HEY shControl or shARNT cell lines after exposure to hypoxia $(0.2 \% 02)$ for $24 \mathrm{hrs} \mathrm{normalized} \mathrm{to}$ 
corresponding shControl normoxia. Mean SEM, $(n=4)$. n.s.,not significant; ${ }^{*}, p<.05 ; * *, p<.01$, unpaired ttest. C) (i) Representative western blot from HEK293 lysates confirming HIF-1 and HIF-2 knockdown. (ii) qRT-PCR analysis of INHA and VEGF mRNA expression in HEK293 cells transfected with either siScr, siHIF-1 , or siHIF-2 and exposed to hypoxia $(0.2 \%$ 02) for $24 \mathrm{hrs}$. Mean SEM, $(n=4) *, p<.05$; **, $p<.01$, Twoway ANOVA followed by Tukeys multiple comparison test. D) qRT-PCR analysis of primers that amplify a proximal HRE region in the INHA promoter (Methods and Supp Fig. 3A) after ChIP of HIF-1 with HIF-1 antibody (Methods) in OVCAR5 and OV90 cells. ChIP qRT-PCR results were quantified as normalized enrichment over IgG and normalized to normoxia. Mean SEM, OVCAR5 $(n=3)$, OV90 $(n=2)$. n.s.,not significant; *, $\mathrm{p}<.05 ; * \star, p<.01$, Two-way ANOVA followed by Fishers LSD test E) Luciferase activity of HEK293 cells transfected with pGL4.10 luciferase reporter containing a 547bp piece of the INHA promoter and SV-40 Renilla control vector. Cells were either (i) exposed to hypoxia $(0.2 \% 02)$ or (ii) co-transfected with HIF-1 overexpression plasmid (HIF-1 ODD) and luciferase activity was measured as described in Methods and normalized to either normoxia or PCDNA3.1. Mean SEM, n=3 (Hypoxia), n=2 (HIF-1ODD) *, $\mathrm{p}<.05 ; * \star, \mathrm{p}<.01$, unpaired t-test. 
A

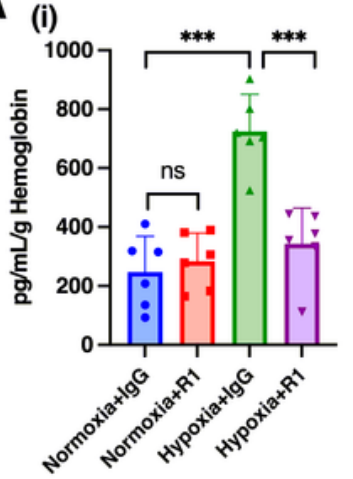

(ii)

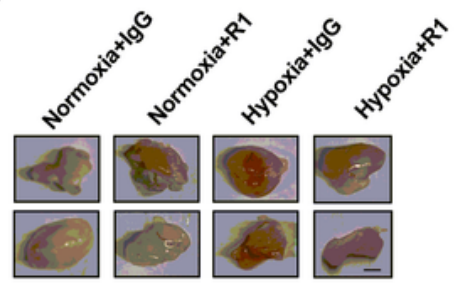

B

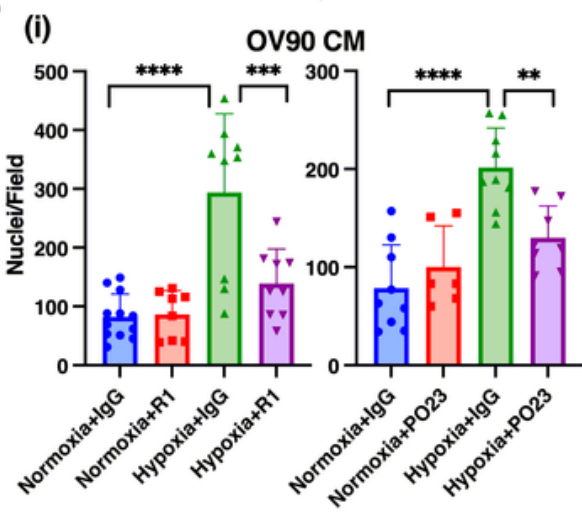

C (i)

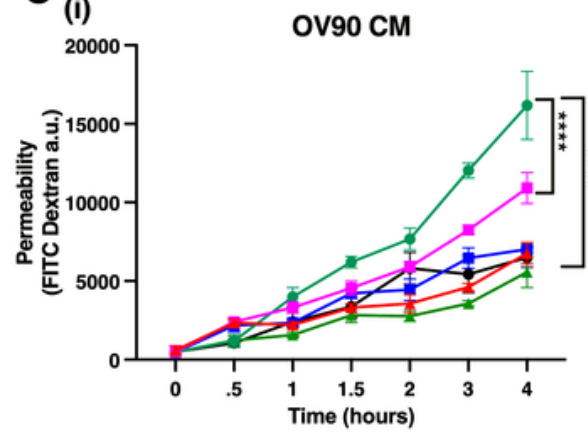

D

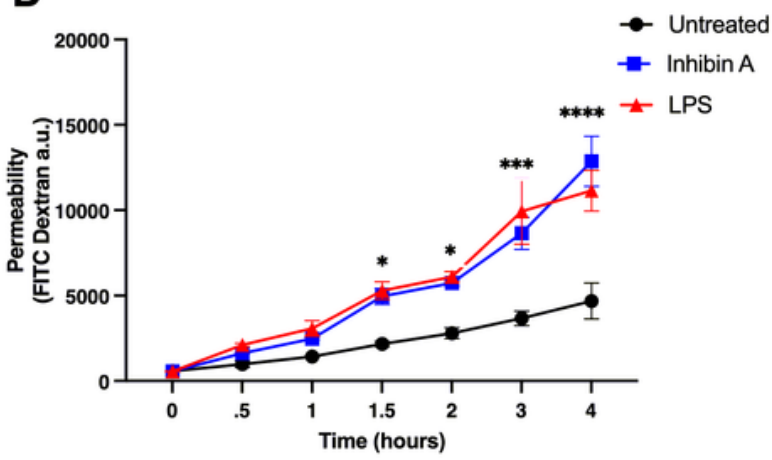

(ii)

(ii)
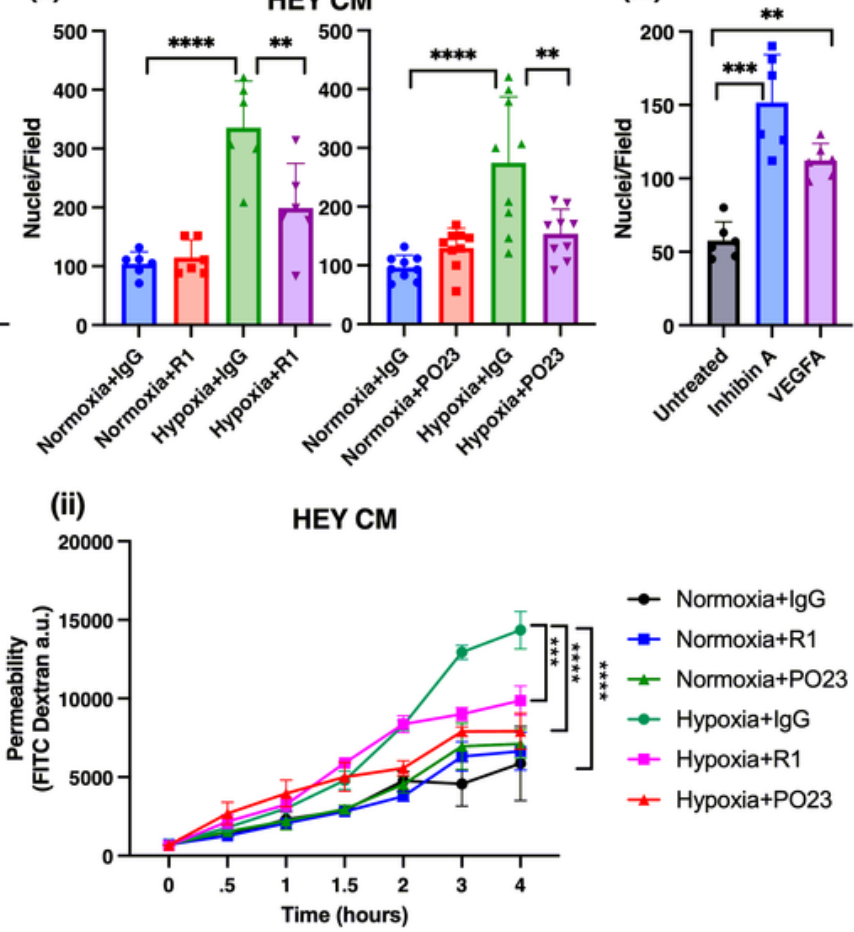

$E_{\text {(i) }}$

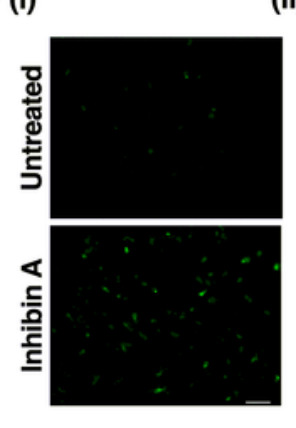

(ii)

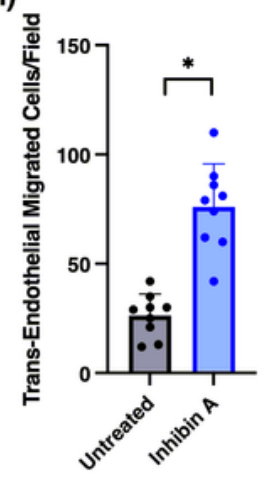

\section{Figure 3}

Inhibin increases hypoxia induced angiogenesis and endothelial cell migration and permeability in vivo and in vitro respectively. A) (i) Hemoglobin content in Matrigel plugs collected 12 days after subcutaneous injection of HEY conditioned media collected from cells exposed to normoxia or hypoxia for $24 \mathrm{hrs}$ and mixed with either $2 \mathrm{~g}$ of IgG or of anti-inhibin R1 antibody. Mean SEM, $\mathrm{n}=6$ plugs per condition. n.s., not significant; ***, p<.001, One-way ANOVA followed by Tukey's multiple comparison test. 
(ii) Representative images of Matrigel plugs from (i) Scale bar: 2mm. B) Quantitation of HMEC-1 migration through fibronectin coated $8 \mathrm{~m}$ trans-well filter (i-ii) towards conditioned media from OV90 or HEY cells exposed to hypoxia $(0.2 \% 02)$ with either $2 \mathrm{~g}$ of $\mathrm{R} 1$ or PO23 anti-inhibin antibody or IgG as a control, or towards (iii) serum free media containing $1 \mathrm{nM}$ inhibin $A$ or $1 \mathrm{nM}$ VEGF A. Nuclei from three representative fields per filter were counted. Mean SD. ${ }^{*}, \mathrm{p}<.01 ;{ }^{* \star *} \mathrm{p}<.001 ; * \star \star \star, p<.0001$, One-way ANOVA followed by Tukey's multiple comparison. C-D) Quantitation of endothelial cell permeability by measuring FITC-dextran changes across a HMEC-1 monolayer treated with (i-ii) conditioned media from (i) OV90 or (ii) HEY cells exposed to hypoxia $(0.2 \% 02)$ with either $2 \mathrm{~g}$ of $\mathrm{R} 1$ or $\mathrm{PO} 23$ anti-inhibin antibody or IgG as a control, or (D) treated with $1 \mathrm{nM}$ inhibin A or $10 \mathrm{~g} / \mathrm{mL}$ LPS. Mean SEM *, $p<.05 ;{ }^{* \star *} \mathrm{p}<.001$; $* \star \star \star, ~ p<.0001$, One-way ANOVA followed by Tukey's multiple comparison. E) HEY trans-endothelial migration (TEM) across HMEC-1 monolayer either treated with inhibin A for 4 hrs or untreated. (i) Representative transmigrated GFP positive HEY cells and (ii) quantitation of transmigration $(n=3) .{ }^{*}, p<.05$, unpaired ttest. Scale bar: $100 \mathrm{~m}$. 
$A_{\text {(i) }}$

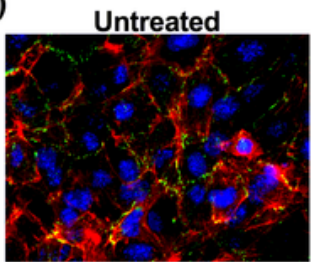

B (i)

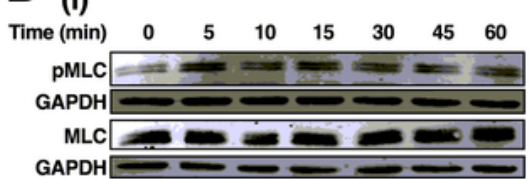

GAPDH

C (i) VE-cadherin Internalization Inhibin A

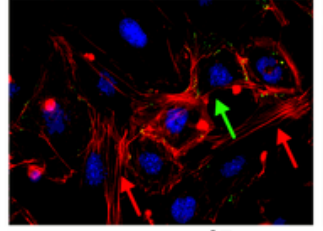

(ii)

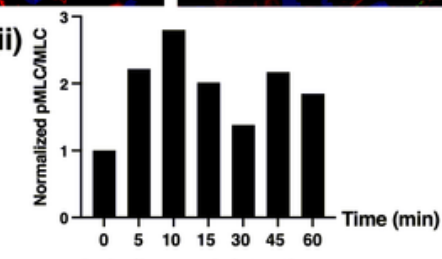

Labeling and detection

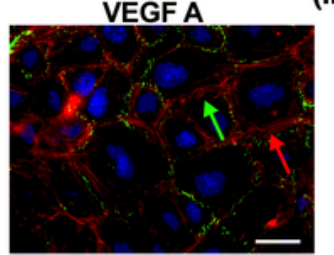

(ii)

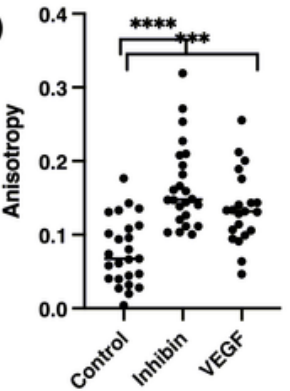

(ii)

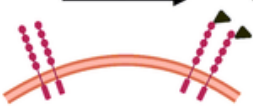
with $2^{\circ}$ antibody

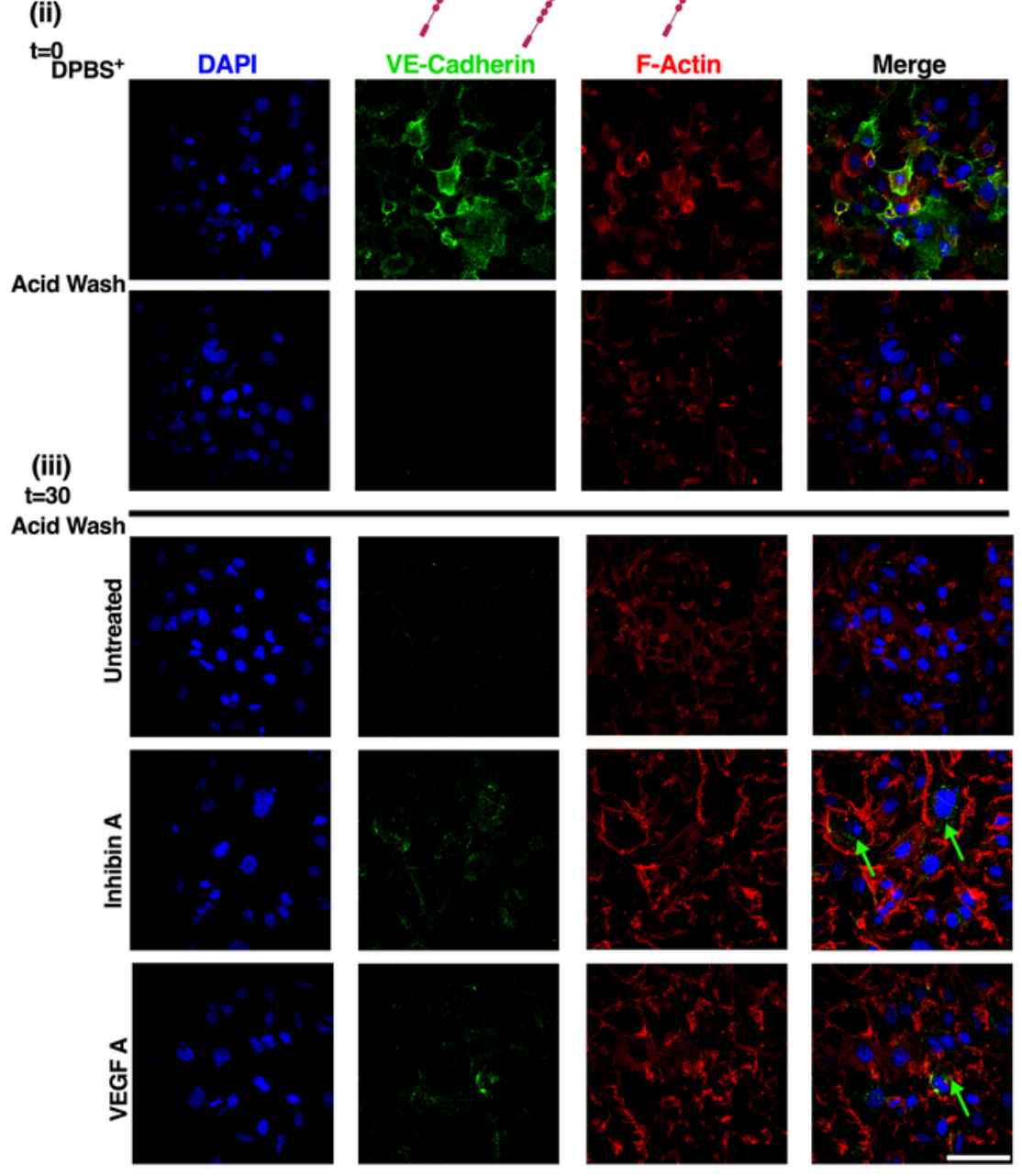

(iv)

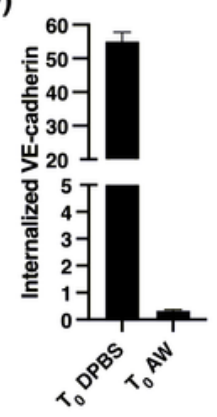

(v)

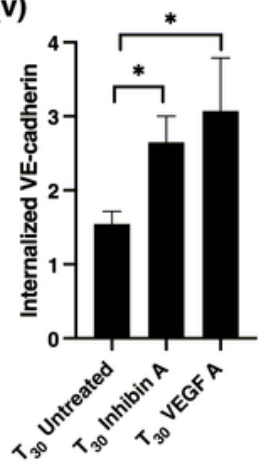

Figure 4

Inhibin increases endothelial cell contractility and VE-cadherin internalization. A) (i) Representative immunofluorescence images of F-actin (red) or VE-Cadherin (green) from HMEC-1 cells grown to confluence on fibronectin coated coverslips and treated with either 1nM inhibin A or 1nM VEGF A for 30 minutes. (ii) Quantitation of actin stress fibers from (i) using ImageJ Fibril tool plugin (Methods). ${ }^{\star * *} p<.001$; ${ }^{* \star \star *}, p<.0001$, unpaired t-test. Scalebar: 25 m. B) (i) Western blot analysis of pMLC-2 from 
HMEC-1 cells upon $1 \mathrm{nM}$ inhibin A treatment for indicated times. (ii) Quantitation of pMLC-2 changes in (i). C) (i) Schematic of VE-cadherin internalization (Methods) (ii) Representative immunofluorescent images of (upper panel) cell surface labeled VE-cadherin at $4 \mathrm{C}$ detected by labeling with an extracellular domain anti-VE-cadherin antibody. (Lower panel) efficiency of stripping of extracellular labeled VEcadherin with a mild acid. (iii) Internalized VE-Cadherin at $37 \mathrm{C}$ detected with a FITC-secondary antibody in either untreated or cells treated with 1nM inhibin A or 1nM VEGF $A$ after acid wash. Green arrows represent internalized VE-cadherin. Red, actin. Blue, DAPI. Quantitation of internalized VE-Cadherin at (iv) T0 or (v) T30 by Blobfinder Image J Plugin (Methods). *, p<.05, unpaired t-test. Scalebar: $25 \mathrm{~m}$. 
A

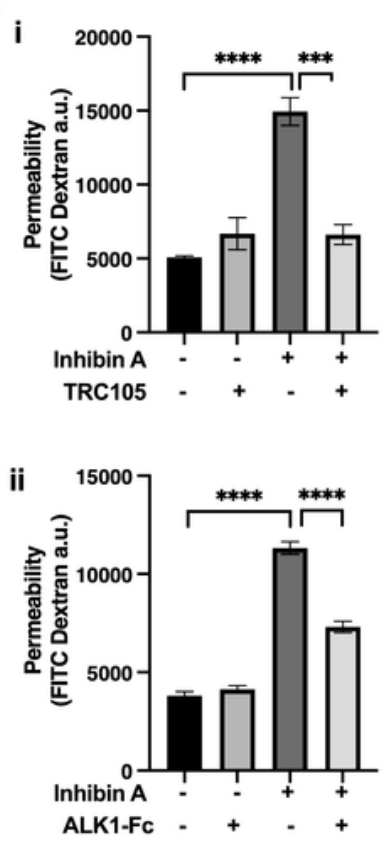

B

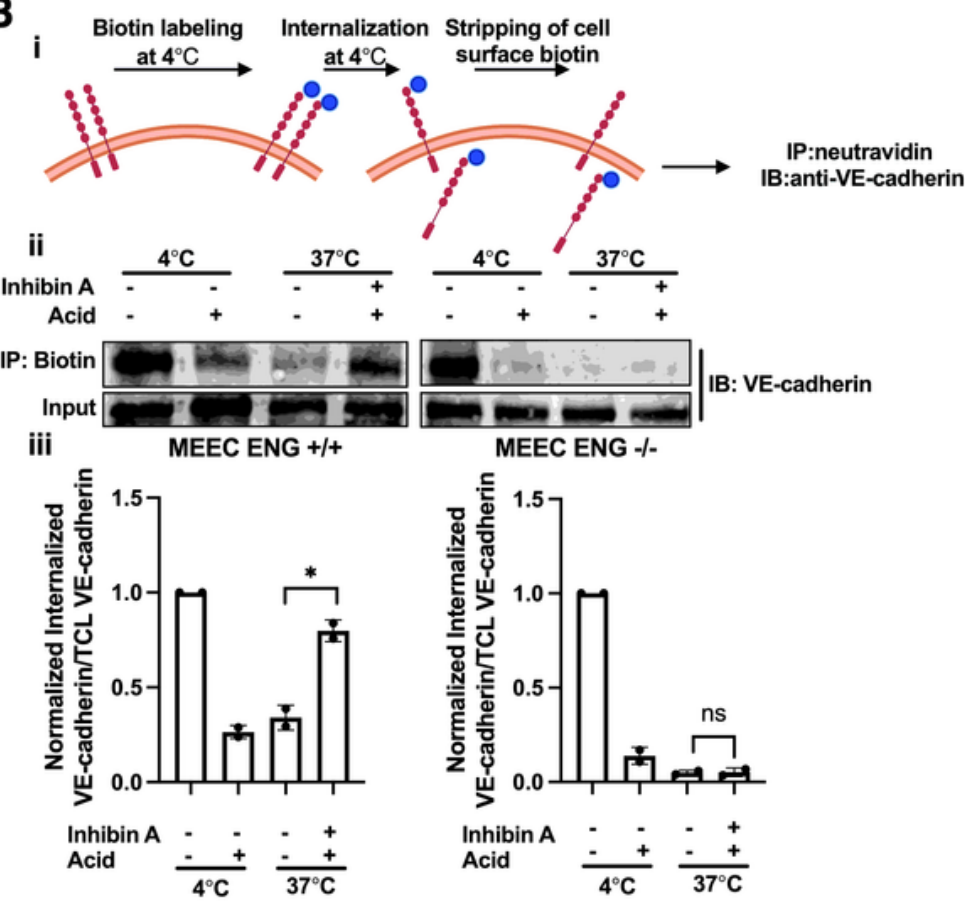

C
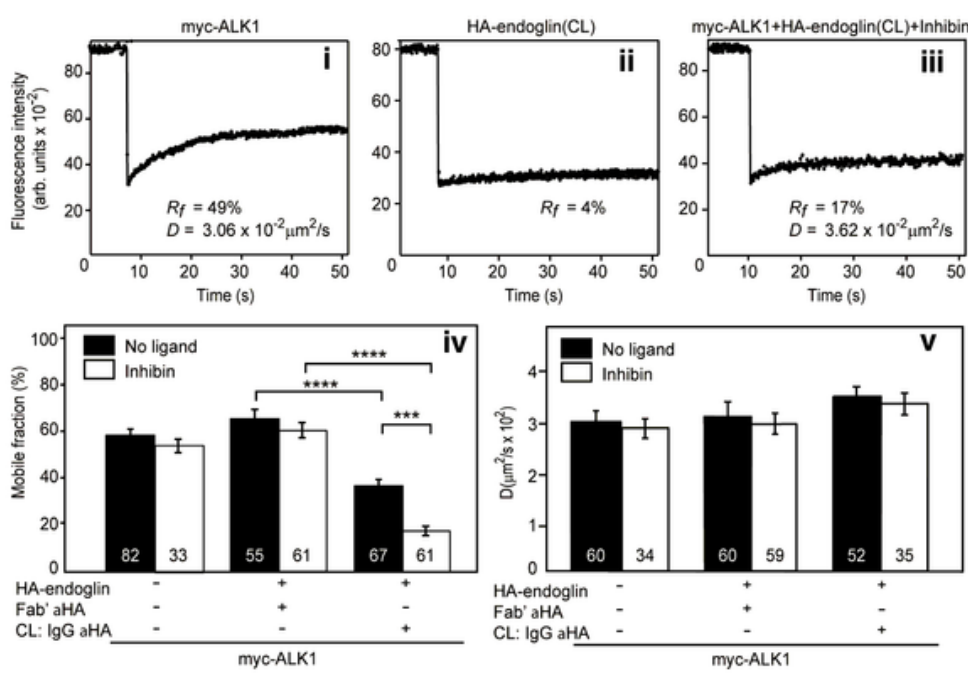

D
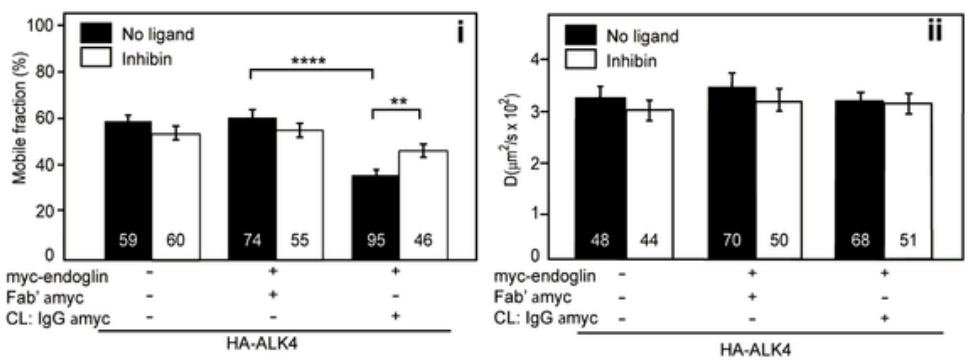

\section{Figure 5}

Inhibin promotes endothelial cell permeability via ALK1 and endoglin and specifically increases ALK1endoglin cell surface complexes while reducing ALK4-endoglin complexes. A) Quantitation of endothelial cell permeability by measuring FITC-dextran changes across a HMEC-1 monolayer treated with 1nM inhibin $A$ in the presence or absence of (i) $100 \mathrm{~g} / \mathrm{mL}$ TRC-105 or (ii) 10ng/mL ALK1-Fc. FITC-dextran diffusion across the HMEC-1 monolayer at 4 hrs is presented. Mean SD, $n=4$ for $i$ and $n=3$ for ii. n.s., not 
significant; $\left.{ }^{\star \star \star}, p<.001 ; * \star \star \star, ~ p<.0001 . B\right)$ Internalization of VE-cadherin measured by cell surface biotinylation. (i) Biotin labeling of cell surface proteins was performed on MEEC WT or MEEC ENG-/-. Internalization was induced by treatment with $1 \mathrm{~nm}$ Inhibin A for 30 minutes at $37 \mathrm{C}$ followed by stripping of cell surface biotin. Internalized VE-cadherin was detected by IP with neutravidin resin and (ii) immunoblotting with anti-VE-cadherin and (iii) quantitated as internalized VE-cadherin over input VEcadherin normalized to $37 \mathrm{C}$ control. Mean SD, $n=2$. n.s., not significant; ${ }^{*}, p<.05$, unpaired t-test. C-D) Patch/FRAP studies on the effect of Inhibin A on endoglin-ALK1 (C) and endoglin-ALK4 (D) complex formation. COS7 cells were transfected with myc-ALK1 and HA-endoglin (C) or with (each vector mycALK4 and HA- endoglin (D) (each vector alone, or together). C) After $24 \mathrm{~h}$, singly transfected cells were labeled for FRAP by anti-tag Fab' followed by fluorescent secondary Fab' (Methods) and subjected to FRAP studies. For patch/FRAP, cells were subjected to protocol 1 of IgG-mediated patching/cross-linking (CL) (Methods), resulting in HA-endoglin patched and labeled by Alexa 488-G R IgG (designated "CL: IgG HA"), whereas myc-ALK1 is labeled by monovalent Fab' (with secondary Alexa 546-GaM Fab'). In control experiments without $\mathrm{HA}$-endoglin $\mathrm{CL}$, the IgG labeling of the HA tag was replaced by exclusive Fab' labeling. Where indicated, inhibin A ( $4 \mathrm{nM})$ was added during the fluorescent labeling step and maintained throughout the measurement. Representative FRAP curves are depicted in panels (i-iii), showing the lateral diffusion of singly-expressed myc-ALK1 (i), singly expressed HA-endoglin immobilized by IgG CL (ii) and of myc-ALK1 in the presence of co-expressed and IgG-crosslinked HA-endoglin in the presence of inhibin A (iii). Panels (iv-v) depict average Rf (iv) and D values (v) of multiple experiments. Bars represent Mean \pm SEM values, with the number of measurements (each conducted on a different cell) shown in each bar. Some of these numbers are lower in the D values panels, since only Rf can be extracted from FRAP curves yielding less than $20 \%$ recovery. Asterisks indicate significant differences between the $\mathrm{Rf}$ values of the pairs indicated by brackets ( ${ }^{\star \star \star *}, \mathrm{p}<1 \times 10-15 ; \star \star \star, p=1 \times 10-9$; one-way ANOVA followed by Bonferroni post-hoc test). D) Cells were labeled for patch/FRAP using protocol 2 (Methods), leading to immobilization (CL) of the myc-endoglin and Fab' labeling of HA-ALK4, whose lateral diffusion was then measured by FRAP. (i) Average Rf values. (ii) Average D values. Bars are mean \pm SEM with number of measurements $(n)$ depicted in each bar. Asterisks indicate significant differences between the Rf values of the pairs indicated by brackets $(* \star \star *, p<1 \times 10-15 ; * *, p=5.6 \times 10-3$; one-way ANOVA followed by Bonferroni post-hoc test). No significant differences were found between $D$ values following myc-endoglin immobilization. 


\section{Figure 6.}

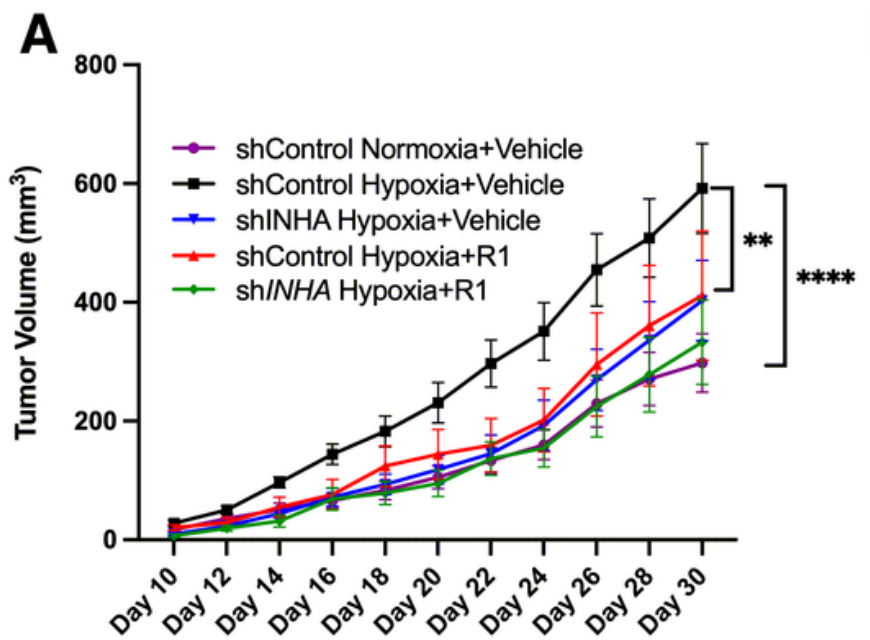

B
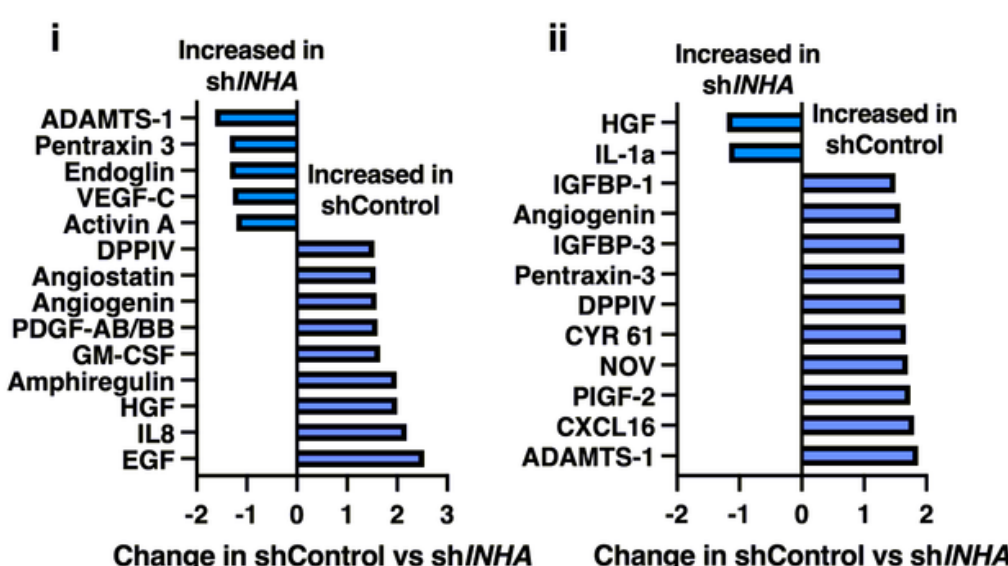

C i

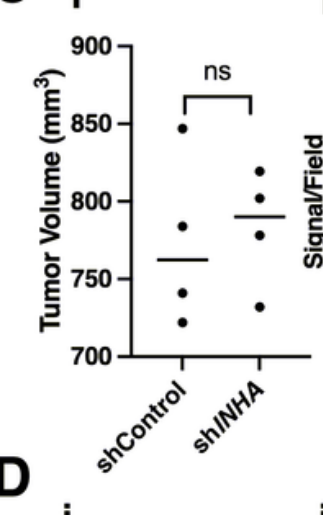

i i

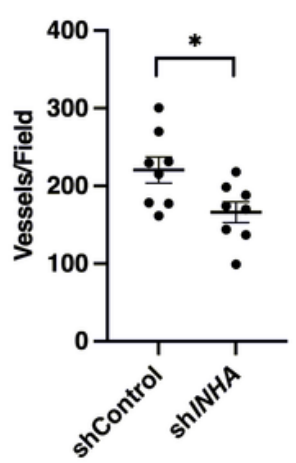

ii

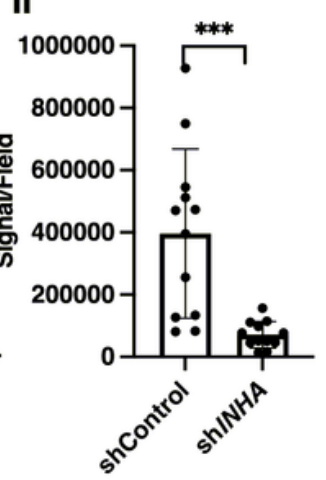

ii

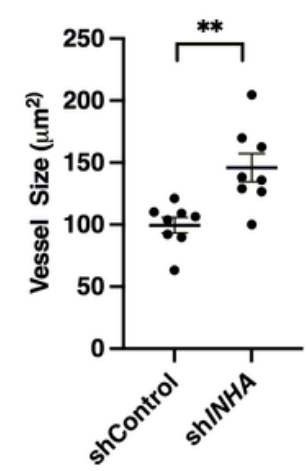

iii

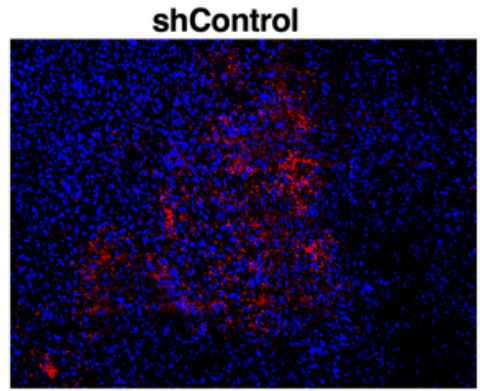

Rhodamine dextran/DAPI

iii

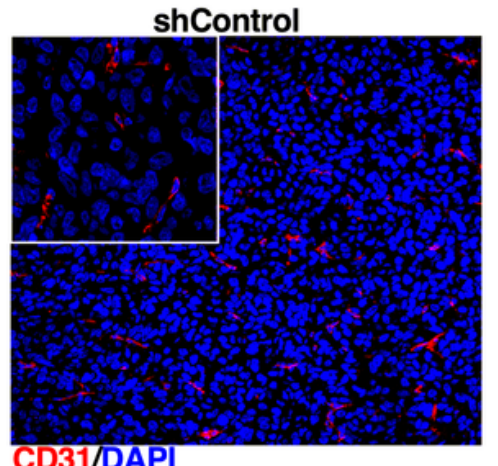

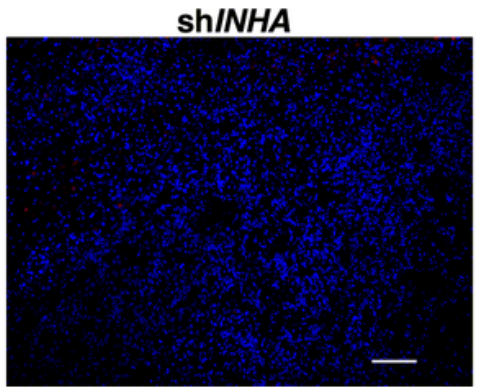

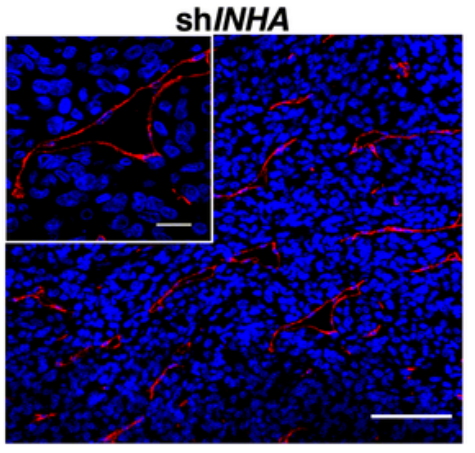

Figure 6

Hypoxia regulated inhibin promotes tumor growth and regulates vascular normalization in vivo. A) Growth curves of subcutaneously implanted HEY shControl or shINHA tumors exposed to either normoxia or hypoxia $(0.2 \% 02) 24 \mathrm{hrs}$ prior to injection. $10 \mathrm{mg} / \mathrm{kg} \mathrm{R} 1$ antibody or vehicle control was intraperitoneally injected three times a week. Mean SEM, $n=10$ for vehicle and $n=6$ for $\mathrm{R} 1$ receiving groups. **, $\mathrm{p}<.01 ; * \star \star *, \mathrm{p}<.0001$, Two-way ANOVA followed by Tukey's multiple comparison test. B) Fold change of proteins most altered in shControl and shINHA tumors (Fig 6A) using the (i) human or (ii) 
mouse angiogenesis proteome array. ( $n=2$ tumors per group).C) (i) Average tumor volume of HEY shControl or shINHA subcutaneous tumors used for analysis of vasculature and permeability in ii and iii. Mean SEM, n=4. (ii) Quantitation of extravasated rhodamine-dextran (red) shown as signal per 10x field from tumors in Fig 6Ci (Methods). Mean SD. $n=12$ fields from 4 tumors. ${ }^{\star * \star}, p<.001$, unpaired t-test. (iii) Representative images of rhodamine-dextran (red) extravasation into either shControl or shINHA subcutaneous tumors from C.i Scalebar:100 m D) (i-ii) Quantitation of average (i) vessel number and (ii) size in a 10x field using ImageJ (Methods). Mean SD. $n=8$ which represents averages of 8 fields in 4 tumors from C.i. (iii) Representative images of CD-31 (red) stained blood vessels in HEY shControl and shINHA subcutaneous tumors from Fig 6Ci. Scalebar:100 m, insets scalebar: 20 m. *, p<.05; **, p<.01, unpaired t-test

\section{Supplementary Files}

This is a list of supplementary files associated with this preprint. Click to download.

- SuppFigforCommsBio.pdf 